\title{
In Situ Secondary Ion Mass Spectrometry Analysis 1992 Summary Report
}

G. S. Groenewold

A. D. Applehans

J. C. Ingram

J. E. Delmore

D. A. Dahl

Published January 1993

Idaho National Engineering Laboratory

EG\&G Idaho, Inc.

Idaho Falls, Idaho 83415

Prepared for the

U.S. Department of Energy

Office of Environmental Restoration and Waste Management

Under DOE Idaho Field Office

Contract DE-AC07-76ID01570 


\section{In Situ Secondary Ion Mass Spectrometry Analysis 1992 Summary Report}

EGG-WTD-10507

Prepared by
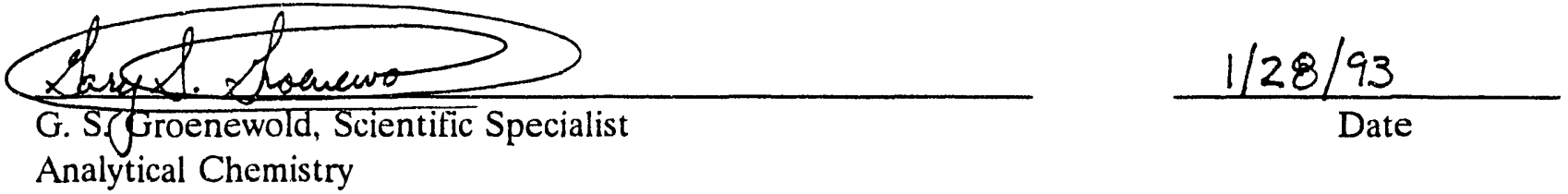

Reviewed by

J.'M. Beller, Senior Project Engineer

Date

Environmental Restoration Technology Development

Approved by

J. M. Beller, Senior Project Engineer

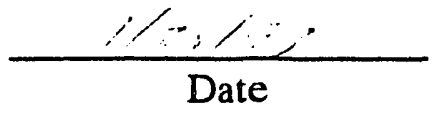

Environmental Restoration Technology Development 


\begin{abstract}
The direct detection of tributyl phosphate (TBP) on rocks using molecular beam surface analysis [MBSA or in situ secondary ion mass spectrometry (SIMS)] is demonstrated. Quantities as low as $250 \mathrm{ng}$ were detected on basalt and sandstone with little or no sample preparation. Detection of TBP on soil has proven to be more problematic and requires further study. Ethylenediaminetetraacetic acid (EDTA) is more difficult to detect because it is very reactive with surfaces of interest. Nevertheless, it is possible to detect EDTA if the acidity of the surface is controlled. The detection of EDTA-metal complexes is currently an open question, but evidence is presented for the detection of ions arising from a EDTA-lead complex. Carboxylic acids (i.e., citric, ascorbic, malic, succinic, malonic, and oxalic) give characteristic SIM spectra, but their detection on sample surfaces awaits evaluation.
\end{abstract}




\section{SLIMMARY}

The in situ secondary ion mass spectrometry (SIMS) analysis program will develop instrumentation and analytical methodologies for analyzing involatile or low volatile analytes present at U.S. Department of Energy sites. This need exists because, in contrast to methods for radionuclides or volatile compounds, techniques for low volatile compounds are not as well developed. Many of the low volatile compounds that this effort addresses can exist in a variety of species in the environment, and there are few techniques that are capable of determining speciation.

Low volatile compounds targeted by this study have the capacity to adsorb to the surfaces of refractory materials and other hard to analyze sample types. Presently, there are few methodologies amenable to the analysis of rocks, soil, concrete, asphalt, and polymers. Standard techniques of sample extraction and laboratory analysis are costly and painstaking for laboratory personnel. Fieldable techniques are needed to provide in-the-field guidance to sampling or remediation crews, and could decrease the cost of remediation by guiding the remediation effort only to those areas where contaminants are being detected. Because timely guidance cannot be provided if the samples have to be transported to a laboratory for analysis, field transportable instrumentation is necessary.

In a SIMS analysis, the surface of a sample is analyzed by bombarding it with a primary particle beam. This event causes secondary particles to be sputtered off the surface and into the gas phase, and some of these particles become charged (i.e., ions). The charged particles are mass analyzed using a mass spectrometer, and the secondary ion mass spectrum that is produced is indicative of the chemical composition of the sample surface. In the event that the surface is contaminated with a chernical, the secondary ion mass spectrum will contain ion signals that originate from the contaminants.

The drawbacks of SIMS are that it normally requires a substantial instrument that must be located in a laboratory environment; accordingly, it has not been used as a field technique. In addition, samples that are nonconductive develop surface charge during SIMS analysis and are not normally been amenable to SIMS analysis without special accommodation for this effect. This accommodation is use of an electron flood gun that adds to the size and complexity of the instrumentation. SIMS has limited capability for analyzing anything beyond the surface (i.e., the bulk) of a sample.

In situ SIMS research has been conducted at the Idaho National Engineering Laboratory (INEL) over the past 10 years with the goals of overcoming some of these limitations, improving on the primary ion gun technology, improving ion optical design to improve detection efficiency, and identifying new applications. The objectives of the program are to combine the new SIMS technologies with ion trap mass spectrometry to directly analyze difficult samples for involatile chemical contaminants, such as chelating compounds, organic acids, and extractants. The goals for this analytical instrumentation/methodology are speed, sensitivity, selectivity, low cost per analysis, and field transportability. The ability of the INEL in situ SIMS technology to detect selected contaminants on selected sample surfaces will also be evaluated.

In FY-92, the direct detection of tributyl phosphate (TBP) on rocks using SIMS was demonstrated. Quantities as low as $250 \mathrm{ng}$ were detected on basalt and sandstone with little or no sample preparation. Detection of TBP on soil has proven to more problematic and is the subject of 
further study. Ethylenediaminetetraacetic acid (EDTA) was more difficult to detect because it is very reactive with surfaces of interest. Nevertheless, it is possible to detect EDTA if the acidity of the surface is controlled. The detection of EDTA-metal complexes was studied, and evidence is presented for the detection of ions arising from a EDTA-lead complex, but the detection of these complexes is currently an open question. Carboxylic acids (i.e., citric, ascorbic, malic, succinic, malonic, and oxalic) give characteristic SIM spectra, but their dectection on sample surfaces awaits evaluation. 


\section{CONTENTS}

ABSTRACT $\ldots \ldots \ldots \ldots \ldots \ldots \ldots \ldots \ldots \ldots \ldots \ldots \ldots \ldots \ldots \ldots \ldots$ iii

SUMMARY $\ldots \ldots \ldots \ldots \ldots \ldots \ldots \ldots \ldots \ldots \ldots \ldots \ldots \ldots \ldots \ldots \ldots$ iv

ACRONYMS $\ldots \ldots \ldots \ldots \ldots \ldots \ldots \ldots \ldots \ldots \ldots \ldots \ldots \ldots \ldots \ldots \ldots \ldots \ldots \ldots \ldots$

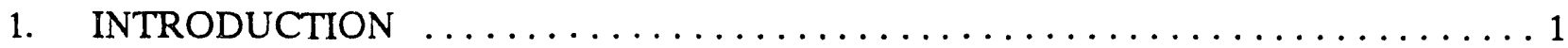

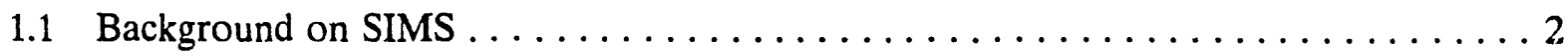

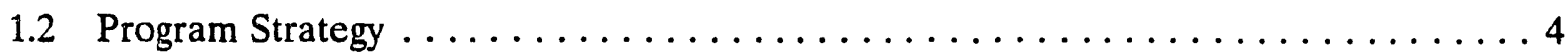

2. IDENTIFICATION OF CHEMICAL ANALYTES AND SAMPLE TYPES FOR

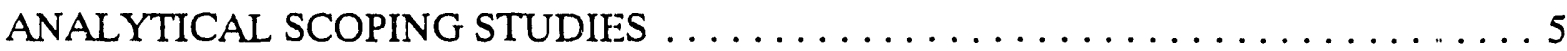

3. EDTA STUDIES $\ldots \ldots \ldots \ldots \ldots \ldots \ldots \ldots \ldots \ldots \ldots \ldots \ldots \ldots \ldots \ldots$

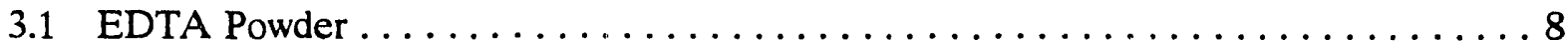

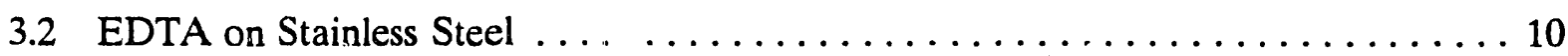

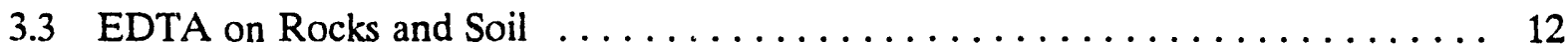

3.4 Disodium EDTA and Disodium Magnesium EDTA $\ldots \ldots \ldots \ldots \ldots \ldots \ldots$

3.5 EDTA with Cobalt(II) and Lead(II) on Stainless Steel . . . . . . . . . . 14

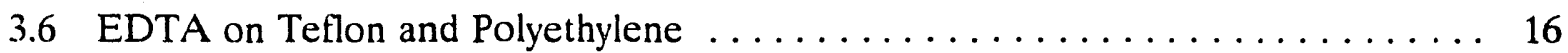

4. TBP STUDIES $\ldots \ldots \ldots \ldots \ldots \ldots \ldots \ldots \ldots \ldots \ldots \ldots \ldots \ldots \ldots \ldots$

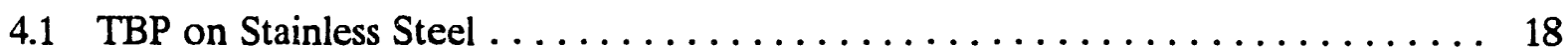

4.2 TBP on Rocks: Basalt and Sandstone $\ldots \ldots \ldots \ldots \ldots \ldots \ldots \ldots \ldots \ldots$

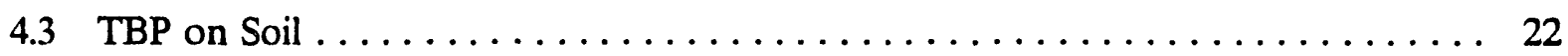

5. CARBOXYLIC ACID STUDIES $\ldots \ldots \ldots \ldots \ldots \ldots \ldots \ldots \ldots \ldots \ldots \ldots \ldots$

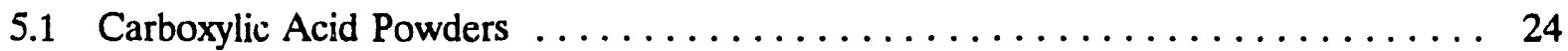

5.2 Carboxylic Acids on Environmental Surfaces $\ldots \ldots \ldots \ldots \ldots \ldots \ldots \ldots$ 
6. CONCLUSIONS AND RECOMMENDATIONS ................ 29

6.1 EDTA and Transition Metals . . . . . . . . . . . . . . . 29

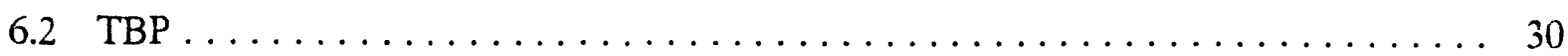

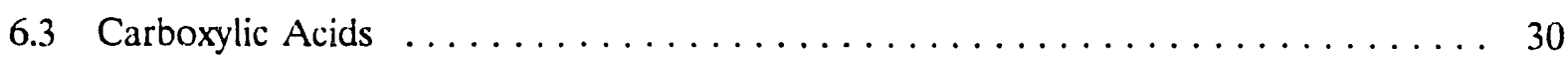

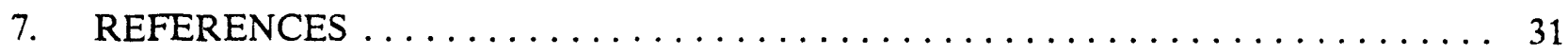

FIGURES

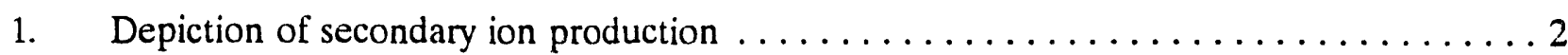

2. Positive ion (top) and negative ion (bottom) spectra of malathion on a morning glory leaf and fragmentation reaction for the production of $\mathrm{m} / \mathrm{z} 157^{-} \ldots \ldots \ldots \ldots \ldots$

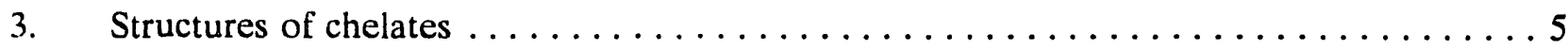

4. Matrix of analytes and sample types for analytical scoping studies $\ldots \ldots \ldots \ldots$

5. Positive ion (top) and negative ion (bottom) spectra of EDTA powder, which was adhered to the target planchette using double-sided tape $\ldots \ldots \ldots \ldots \ldots \ldots \ldots \ldots$

6. High mass expansion of positive ion (top) and negative ion (bottom) spectra of EDTA powder, which was adhered to the target planchette using double-side tape $\ldots \ldots \ldots 8$

7. Rationalization of ions observed in SIM spectrum of EDTA powder, $\underline{m} / \underline{z} 160-88 \ldots \ldots 10$

8. Rationalization of ions observed in SIM spectrum of EDTA powder, $\underline{\mathrm{m} / \mathrm{z}} 61-18 \ldots \ldots 11$

9. Cation (top) and anion (bottom) SIM spectra of EDTA on stainless steel; EDTA

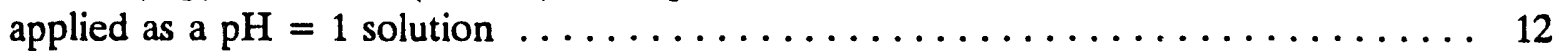

10. SIM spectrum of EDTA applied to stainless steel as a $\mathrm{pH}=10$ solution $\ldots \ldots \ldots 12$

11. $1100 \mathrm{ng}$ of EDTA solution $(\mathrm{pH}=1.0)$ spiked onto a small rock (calcium fluorite) $\ldots$

12. SIM spectrum (cation only) of disodium EDTA powder adhered to a target planchette

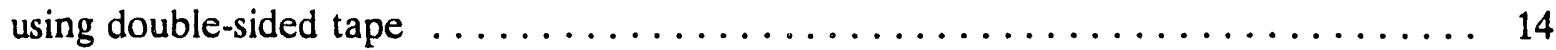

13. Speculative structures for $\mathrm{m} / \mathrm{z} 72^{+}, 200^{+} 255^{+}$observed in the SIM spectrum of

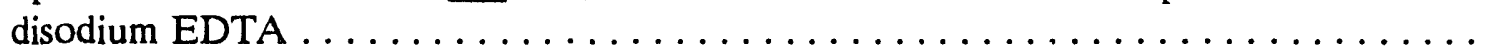


14. Partial cation (top) and anion (bottom) SIM spectrum of cobalt(II) together with EDTA (deposited as a $\mathrm{pH}=1.8\left(\mathrm{Y}^{\circ}\right)$ solution); cobalt(II) was deposited as a $\mathrm{CoCl}_{2}$

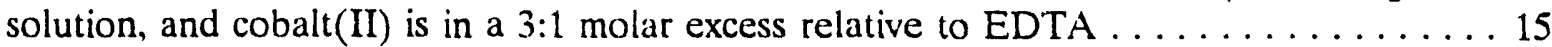

15. Partial cation (top) and anion (bottom) SIM spectrum of lead EDTA on stainless

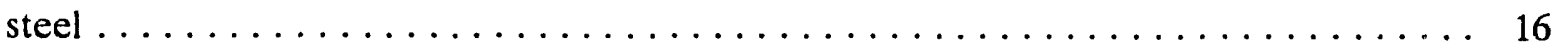

16. Proposed structure for $\mathrm{m} / \mathrm{z} 235^{+}$observed in the SIM spectrum of EDTA on teflon . . 17

17. Cation (top) and anion (bottom) SIM spectrum of TBP on stainless steel . . . . . . 19

18. Structure of TBP, proposed structures of selected ions listed in Table $4 \ldots \ldots \ldots$

19. Cation SIM spectrum of $250 \mathrm{ng}$ of TBP on basalt. No significant anions were

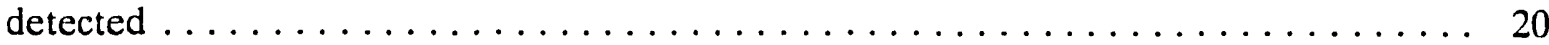

20. Benchmark cation SIM spectrum of (unspiked) basalt $\ldots \ldots \ldots \ldots \ldots \ldots \ldots$

21. Cation SIM spectrum of $250 \mathrm{ng}$ TBP on sandstone $\ldots \ldots \ldots \ldots \ldots \ldots \ldots \ldots$

22. Cation SIM spectrum of benchmark (unspiked) sandstone $\ldots \ldots \ldots \ldots \ldots \ldots \ldots$

23. Cation SIM spectrum of unspiked soil $\ldots \ldots \ldots \ldots \ldots \ldots \ldots \ldots \ldots \ldots \ldots$

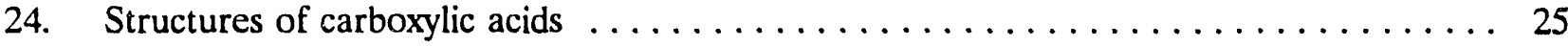

25. Partial cation (top) and anion (bottom) SIM spectra of ascorbic acid powder, which was adhered to the planchette with double-sided tape $\ldots \ldots \ldots \ldots \ldots \ldots \ldots \ldots$

26. Scheme proposed for the formation of $\mathrm{m} / \mathrm{z} 115^{\circ}$ (base peak) in the anion SIM spectrum

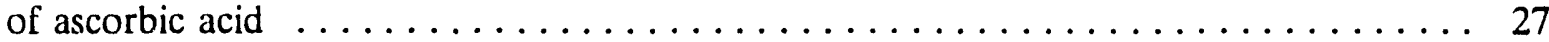

27. Anion SIM spectrum of oxalic acid on stainless steel $\ldots \ldots \ldots \ldots \ldots \ldots \ldots$

\section{TABLES}

1. Explanation of ions observed in SIM spectra of EDTA powder $\ldots \ldots \ldots \ldots \ldots$

2. Ionic form of EDTA as a function of $\mathrm{pH} \ldots \ldots \ldots \ldots \ldots \ldots \ldots \ldots \ldots$

3. Assignment of ions observed in the EDTA lead SIM spectra $\ldots \ldots \ldots \ldots \ldots$

4. Assignment of ions observed in the SIM spectra of neat TBP on stainless steci $\ldots \ldots 18$

5. Assignment of cations observed in the SIM spectrum of TBP on basalt $\ldots \ldots \ldots 21$ 
6. Assignment of cations observed in the SIM spectrum of $250 \mathrm{ng}$ TBP on sandstone ... 21

7. Summary of salient cations observed in the SIM spectra of carboxylic acid powders ... 25

8. Summary of salient anions observed in the SIM spectra of carboxylic acid powders . . . 26 


\section{ACRONYMS}

CLP

DOE

EDTA

EPA

DTPA

GC/MS

INEL

MBSA

$\underline{\mathrm{m} / \mathrm{z}}$

NTA

$\mathrm{ReO}_{4}^{-}$

SIMS

TBP
Contract laboratory program

U.S. Department of Energy

Ethylenediaminetetraacetic acid

Environmental Protection Agency

Diethylenetriaminepentaacetic acid

Gas chromatography/mass spectrometry

Idaho National Engineering Laboratory

Molecular beam surface analysis

Mass to charge ratio

Nitriloacetic acid

Rhenium tetroxide, or perrhenate, anion

Secondary ion mass spectrometry

Tributyl phosphate 


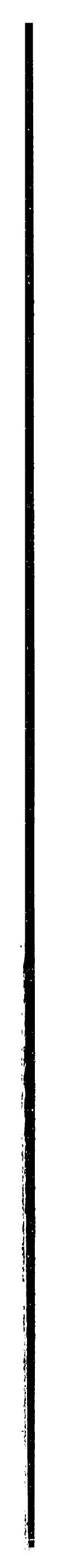




\section{In Situ Secondary Ion Mass Spectrometry Analysis 1992 Summary Repoit}

\section{INTRODUCTION}

The purpose of this program is to develop instrumentation and analytical methodology for the analysis of involatile or low volatile analytes present at U. S. Department of Energy (DOE) sites. A need exists for analytical methods capable of analyzing low volatile compounds. This need exists because, in contrast to methods for radionuclides or volatile compounds, techniques for low volatile compounds are not as well developed. Many of the low volatile compounds that this effort is addressing can exist in a variety of species in the environment, and there are few techniques that are capable of determining speciation. An example of the problem is ethylenediaminetetraacetic acid (EDTA), which can exist as six different species depending on the $\mathrm{pH}$ of its environment. When the compound is in the presence of metal ions, the number of forms the compound can take is increased. Metals themselves (e.g., plutonium and cobalt) can exist in a variety of oxidation states and oxide forms in the environment. The speciation of low volatile compounds is important because it can dramatically affect the mobility of the chemicals and thus impact the risk posed by them.

Low volatile compounds targeted by this study have the capacity to adsorb to the surfaces of refractory materials and other hard to analyze sample types. At the present time, there are few attractive methodologies that are amenable to the analysis of materials such as rocks, soil, concrete, asphalt, and polymers. The standard technique is to perform an exhaustive extraction of the sample, followed by laboratory analysis. This activity is limited to the laboratory and is frequently costly and painstaking for laboratory personnel.

Fieldable techniques are needed to provide in-the-field guidance to sampling or remediation crews. Fieldable techniques could decrease the cost of remediation by guiding the remediation effort only to those areas where contaminants are being detected. Timely guidance cannot be provided if the samples have to be transported to a laboratory for analysis. Hence, a need exists for field transportable instrumentation.

Involatile and low volatile compounds are important at DOE waste disposal sites. For this report, chelating agents, organic acids, and extractants are included in the low volatile-involatile category. Generally, these compounds are not toxic in and of themselves. However, these compounds have been disposed of with radionuclides and toxic metals, forming complexes with these metals, and it is known that these complexes have enhanced mobility in the environment relative to the uncomplexed species. A highly mobile, complexed radionuclide or toxic metal poses a much different risk than an immobile, uncomplexed species. Accordingly, analytical methodologies that can address speciation of the radionuclides and toxic metals cons itute an important need.

A need exists for detection instrumentation and methodologies that address these issues. The desired technology needs to be small, transportable, selective (i.e., able to detect contaminants in the presence of an environmental background), sensitive (i.e., to the level where risk is negligible), modest in cost, and versatile (i.e., able to analyze for a variety of compounds). 


\subsection{Background on SiMS}

Secondary ion mass spectrometry (SIMS) is an analysis technique where the surface of a sample is bombarded with a primary particle beam. This event causes secondary particles to be sputtered off the surface and into the gas phase, and some of these particles will be charged (i.e., ions) (see Figure 1). The charged particles can be mass analyzed using a mass spectrometer, and the secondary ion mass spectrum that is produced is indicative of the chemical composition of the sample surface. In the event that the surface is contaminated with a chemical, the secondary ion mass spectrum will contain ion signals that will originate from the contaminants.

SIMS is a very sensitive technique for the analysis of involatile analytes existing on the surface of samples. In this regard, it is very different from analytical techniques that require the analyte compounds to volatilize; an example of this would be gas chromatography/mass spectrometry (GC/MS) in which analytes must be extracted from the samples and then injected into the GC/MS, where they are volatilized as part of the analysis process. GC/MS data is normally interpreted only in terms of bulk concentration.

SiMS does have some drawbacks. It normally requires a substantial instrument that must be located in a laboratory environment; hence, it has not been used as a field technique. Samples that do not conduct develop surface charge during SIMS analysis, and these have not normally been amenable to SIMS analysis without special accommodation for this effect. This accommodation has normally been the utilization of an electron flood gun, which adds to the size and complexity of the instrumentation. SIMS has very limited capability for analyzing anything beyond the surface (i.e., the bulk) of a sample.

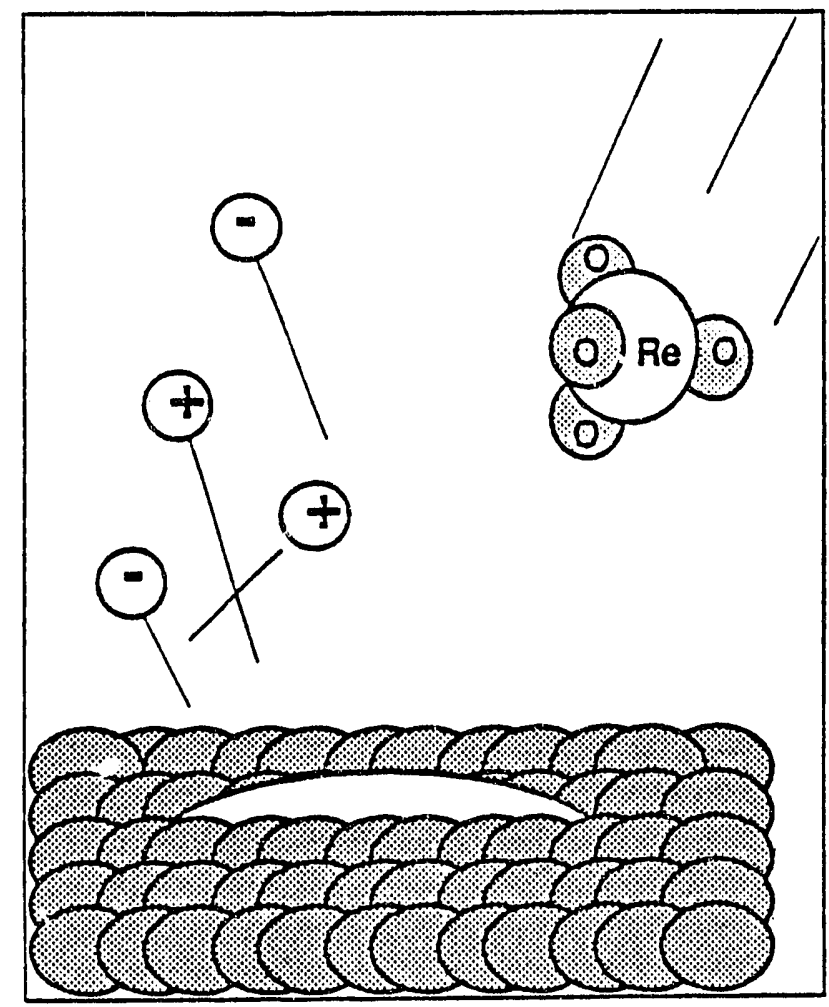

Figure 1. Depiction of secondary ion production. 
SIMS research has been conducted at the Idaho National Engineering Laboratory (INEL) over the past 10 years with the goals of overcoming some of the limitations, improving on the primary ion gun technology, improving ion optical design to improve detection efficiency, and identifying new applications. This research produced a new primary ion gun capable of producing massive [rhenium tetroxide or perrhenate $\left(\mathrm{ReO}_{4^{-}}\right)$] anions; these anions are very efficient for producing secondary ions. Ion optical modeling using the SIMION code resulted in lens design that improved ion transmission from the sputtering region to the mass analyzer and resulted in improved sensitivity. A pulsed extraction system was developed to eliminate sample surface charging; this development makes even the most insulating samples amenable to SIMS analysis without the need for an electron flood gun, and it allows the anion and cation secondary ion mass spectra to be collected at the same time.

These developments have been combined in a single instrument at the INEL, and the combined technology is referred to as molecular beam surface analysis (MBSA). The technology was used for the direct detection of the organophosphothioate pesticide malathion on morning glory leaves. ${ }^{1}$ Direct detection in this context means virtually no sample preparation (i.e., extraction, concentration, separation) was needed. The leaf was sampled using a hole punch, and the resulting disk was attached to a target planchette using double-sided tape. The planchette was admitted to the instrument through a vacuum lock, and a secondary ion mass spectrum was acquired. The whole process required less than 10 minutes. A mass spectrum characteristic of malathion was observed, and $10 \mathrm{ng}$ was easily detected using the mass to charge ratio $(\underline{\mathrm{m} / \mathrm{z}}) 157^{\circ}$ ion (see Figure 2 ). These results indicated that MBSA had capability for rapid analysis of involatile contaminants on difficult-to-handle samples.

The MBSA technology was developed at the INEL using a quadrupole mass spectrometer. Concurrently, a new generation of mass detectors was developed. The new, ion trap mass spectrometers are smaller in size than quadrupole instruments, have higher sensitivity, and have lower pumping requirements than quadrupoles because they operate at higher source pressures. Thus, the development of this type of mass detector is germane to the in situ SIMS effort because the ion trap

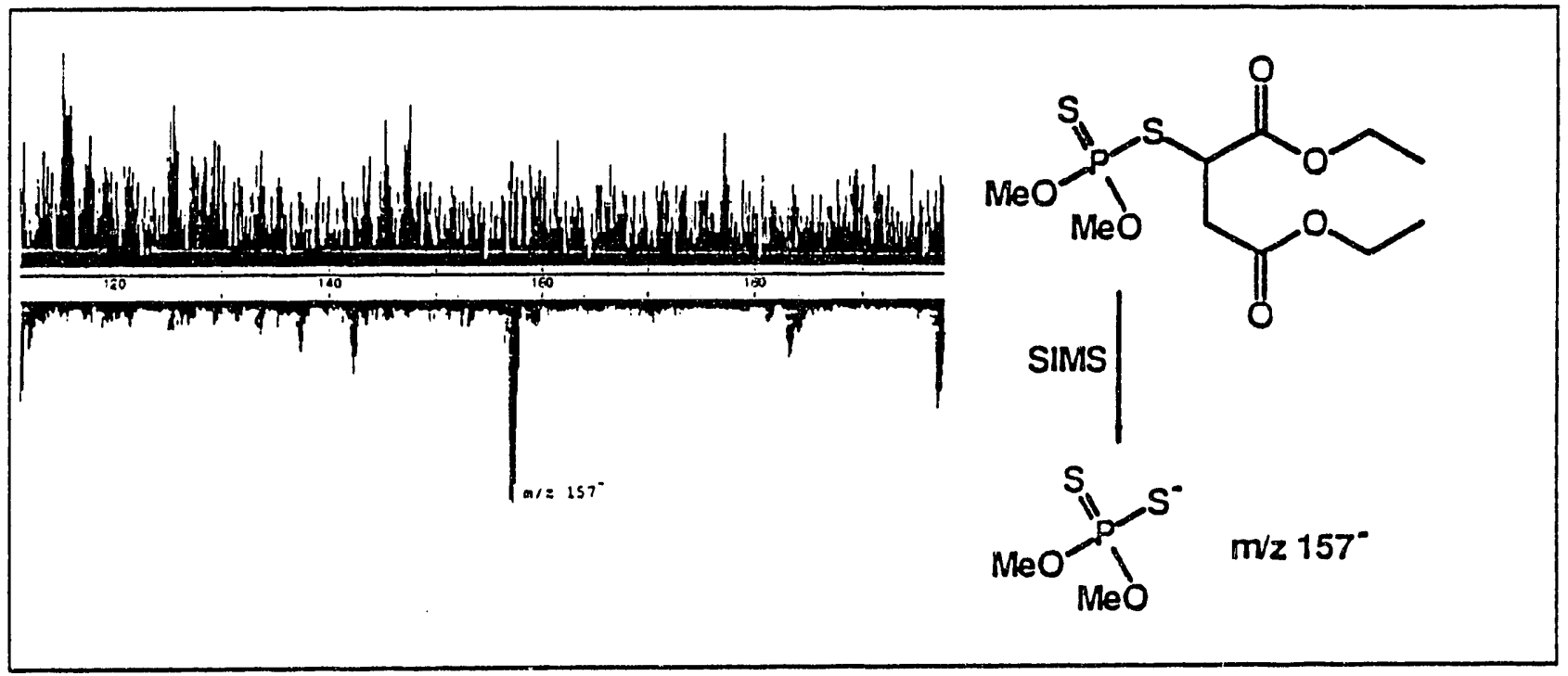

Figure 2. Positive ion (top) and negative ion (bottom) spectra of malathion on a morning glory leaf and fragmentation reaction for the production of $\mathrm{m} / \mathrm{z} 157^{\circ}$. 
offers the potential for field transportability. In addition, there are substantial improvements in specificity possible with ion trap mass spectrometers because they are capable of high resolution accurate mass measurement (for elemental composition assignment), and they can perform mass spectrometry/mass spectrometry.

\subsection{Program Strategy}

The long-term strategy for the in situ SIMS program is to combine the new INEL SIMS technologies with ion trap mass spectrometry for the purpose of directly analyzing difficult samples for involatile chemical contaminants, such as chelating compounds, organic acids, and extractants. The goals for this analytical instrumentation/methodology are speed, sensitivity, selectivity, low cost per analysis, and field transportability. In the near term, however, it was important to evaluate the efficacy of the INEL SIMS technology for the detection of selected contaminants on selected sample surfaces, and analytical scoping studies were initiated in fiscal year 1992 for this purpose. It is the intent of this report to relay the results of these scoping studies.

The 1992 scoping studies consisted of several tasks:

- Identify target analytes and sampie types

- Analyze target analytes, alone and deposited on samples

- Interpret spectra to determine potential analytical utility

- Recommend areas for further investigation.

The scoping studies were performed utilized the existing INEL MBSA instrument. 


\section{IDENTIFICATION OF CHEMICAL ANALYTES AND SAMPLE TYPES FOR ANALYTICAL SCOPING STUDIES}

Analytical methods for the detection of involatile coritaminants are poorly developed at this time. A class of compounds that has few analytical methods is the chelating agents. This class includes EDTA, diethylenetriaminepentaacetic acid (DTPA), and nitriloacetic acid (NTA) (see Figure 3). These compunds were used as purification and decontamination agents at DOE sites and were disposed of with radionuclides at waste disposal sites. Another class of compounds used for similar purposes is small organic acids, namely citric acid, oxalic acid, and ascorbic acid. A third class of compounds is the alkyl phosphates, which are used as extractants and solvent modifiers in the handling of uranium and plutonium. There is little information on the presence of these compounds at DOE waste disposal sites. Riley and Zachara state that the "absence of data on alkyl phosphates, complexing agents, and organic acids is due to several factors, including (1) the site-specific nature of the constituents, (2) the lack of regulation, and (3) limitations of the analytical measurement technique." 2 These authors further explain that since the chemicals are unregulated, "they are not routinely measured as part of environmental compliance programs, and that analytical sampling and measurement methodologies may be inadequate to accurately measure, monitor, or even detect these constituents in the environment." As a result, these classes of compounds "may be far more common than is suggested by the monitoring and characterization data from the 91 waste sites."

The reason why these classes of cumpounds have not been routinely monitored is because they are not toxic or otherwise hazardous by themselves. Unfortunately, the chelating agents and organic acids form strong complexes with radionuclides and toxic metals, and it is known that the

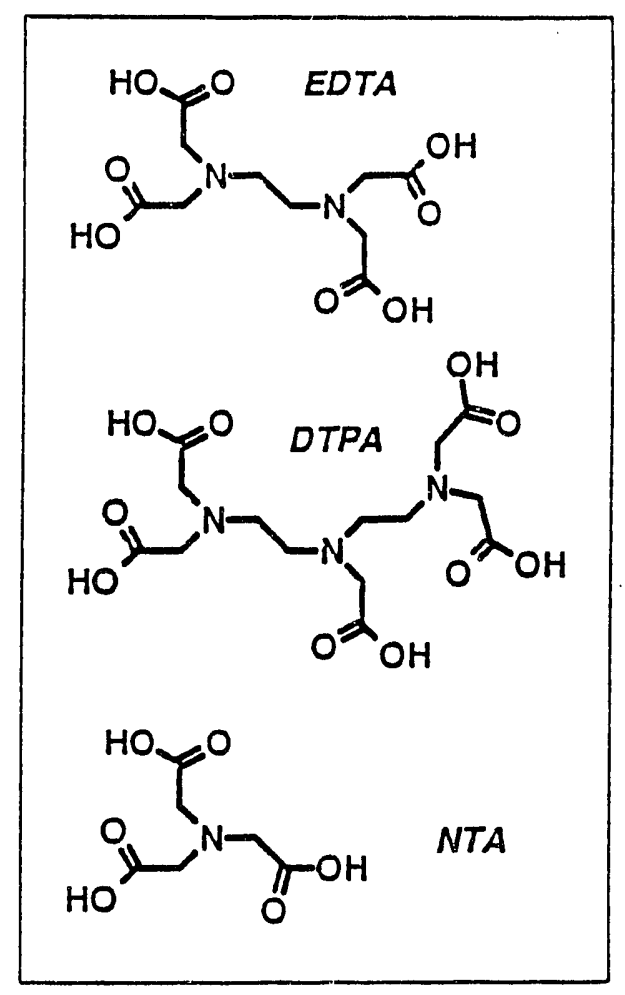

Figure 3. Structures of chelates. 
environmental mobility of the complexed metals can be substantially greater than the mobility of the uncomplexed metals. ${ }^{3}$ For example, soluble plutonium was ubserved to be predominantly in an anionic form in water from the Maxey Flats waste disposal site, ${ }^{4,5}$ and a similar observation has been made for cobalt at Oak Ridge. ${ }^{6}$ These observations are explained in terms of these metals existing as complexes with chelating agents, most likely EDTA. The study by Means, et. al, showed that sorption of ${ }^{60} \mathrm{Co}$ to sediment dropped by 3 to 4 orders of magnitude in the presence of EDTA and concluded that "mobilization rates may be accelerated by several orders of magnitude." 6

There is additional motivation for developing rapid detection technology for tributyl phosphate (TBP). TBP was commonly buried with plutonium waste, and accordingly, the presence of TBP may serve as a valuable indicator of potential plutonium contamination. Such an indicator would be important because plutonium analysis using alpha spectrometry is painstaking, time-consuming, and costly. Any technique that would decrease the number of negative plutonium analyses would have the effect of improving the efficiency of plutonium sampling and analysis efforts. TBP can be analyzed using the Environmental Protection Agency (EPA) contract laboratory program (CLP) procedure for semivolatile organic compounds, but this analysis suffers from the same drawbacks as alpha spectrometry. A need exists for a more rapid detection method for TBP.

Radionuclides and toxic metals can exist as a variety of different chemical species. For example, plutonium exists in the III, IV, V, and VI oxidation states, exists as an oxide, and is readily chelated in the presence of EDTA or other agents. The oxidation state of a metal affects the stability of the metal-chelate complex. The chemical species that the metal exists in has an important bearing on the environmental mobility of the metal, risk posed by the metal, and choice of remediation methodology. Accordingly, a basic research need exists to identify and develop analytical techniques to determine speciation or radionuclides in different types of waste forms, ${ }^{7}$ and access to speciation information would have a positive impact on problems such as the Hanford Underground Storage Tanks. $^{8}$

Nontypical sample types exist at DOE waste disposal sites that are not readily amenable to conventional analytical methodologies, i.e., extraction, followed by concentration, and finally analysis. Sample types that would be difficult to extract but nevertheless need analysis include rocks, concrete, asphalt, wood, and selected plastics. In addition, methods for analyzing sand and soil that do not require extraction are desired because of the expense and time delays associated with laboratory extraction of samples. Examples of sites where these sample types exist are Pad A of the INEL's Radioactive Waste Management Complex ${ }^{9}$ and Test Reactor Area Warm Waste Pond. ${ }^{10}$ An examination of documentation of Rocky Flats waste shipped to the INEL confirms that the ability to analyze these sample types is desirable. ${ }^{a}$

The considerations discussed above were used to generate a test matrix (see Figure 4); the purpose of this test matrix was to provide guidance to the analytical scoping studies specified for the in situ SIMS program. The work of Riley and Zachara was helpful in developing this matrix. ${ }^{2}$ Ideally,

a. T. J. Clements, Content Code Assessments for INEL Contact-Handled Stored Transuranic Wastes, EG\&G Idaho, Inc., WM-F1-82-021, October 1982. 


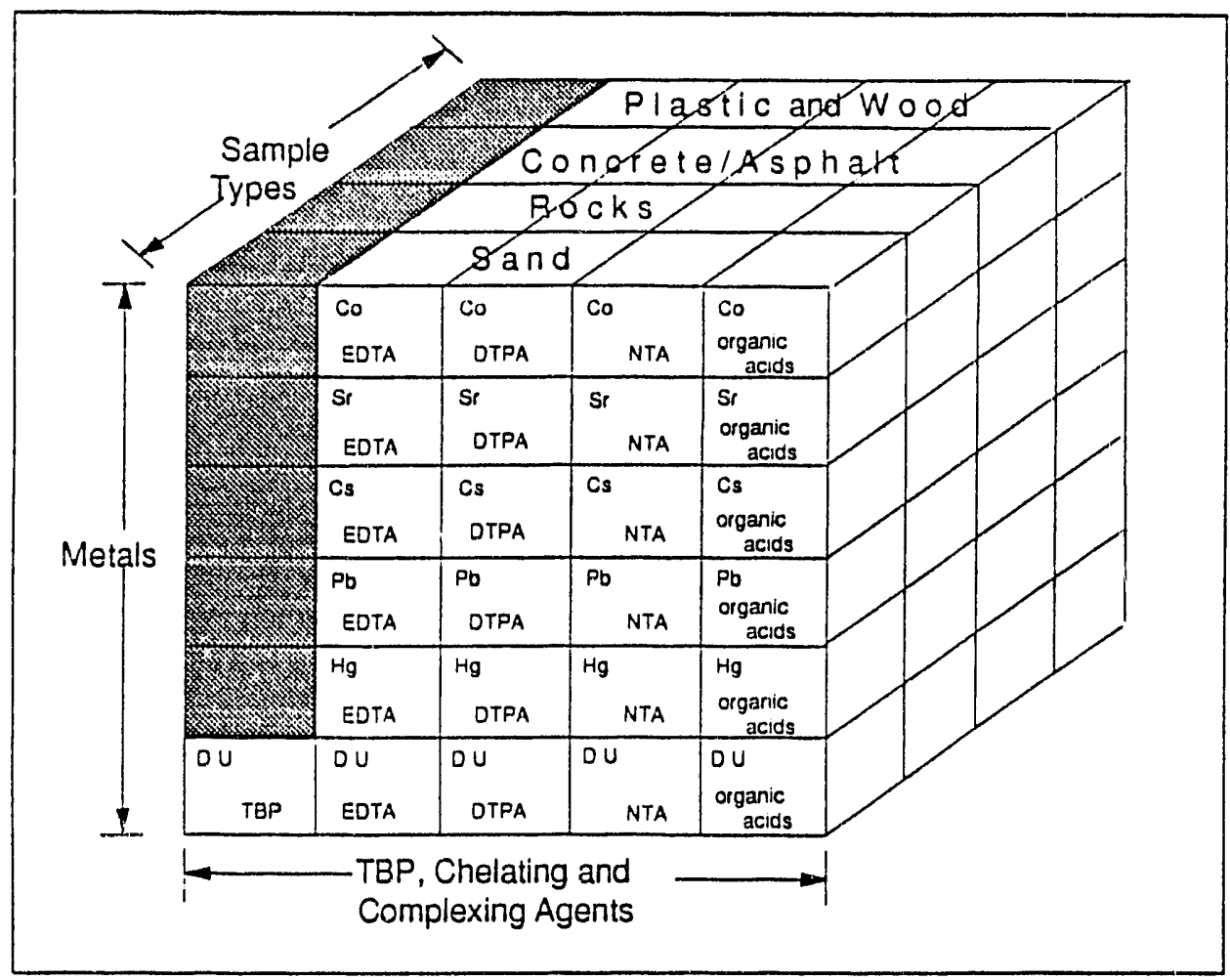

Figure 4. Matrix of analytes and sample types for analytical scoping studies.

the in situ SIMS program would generate technology/methodology that would be able to address all of the targets, samples, and combinations indicated by the test matrix. In actuality, however, no panacea is likely to be identified, and the purpose of the scoping studies is to identify those sample types and analytes that are especially amenable to analysis by MBSA.

It was impossible to get through the entire matrix in a single year. Accordingly, those analytes and sample types were focused on that were, in our opinion, of greatest interest from an environmental contamination perspective.

Analytes

- $\quad$ TBP

- $\quad$ EDTA

- Small organic acids: acetic, oxalic, and citric

- Lead

- Cobalt
Sample Types

- Soil

- Small rocks

Lead was analyzed for two reasons. First, it is a toxic metal that is a known contaminant; second, it serves as a heavy metal simulant for the transuranic metals without creating problems associated with handling radioactive materials.

In the following sections, the analytical scoping studies performed to date on an analyte-by-analyte basis are reviewed. 


\section{EDTA STUDIES}

EDTA acid was studied on a variety of different substrates to understand its fragmentation chemistiy under SIMS bombardment and to identify characteristic ions useful for detection purposes.

\subsection{EDTA Powder}

The first experiments that were conducted involved analyzing EDTA powder (as the tetraacid), which had been attached to a target planchette using double-sided tape, admitted to the MBSA instrument, and analyzed. Positive (cation) and negative (anion) spectra were acquired and are shown in Figures 5 (full spectrum) and 6 (expansion). These spectra contained a large number of ions that were ascribed to EDTA (as opposed to the double-sided tape), and this finding indicates that it may

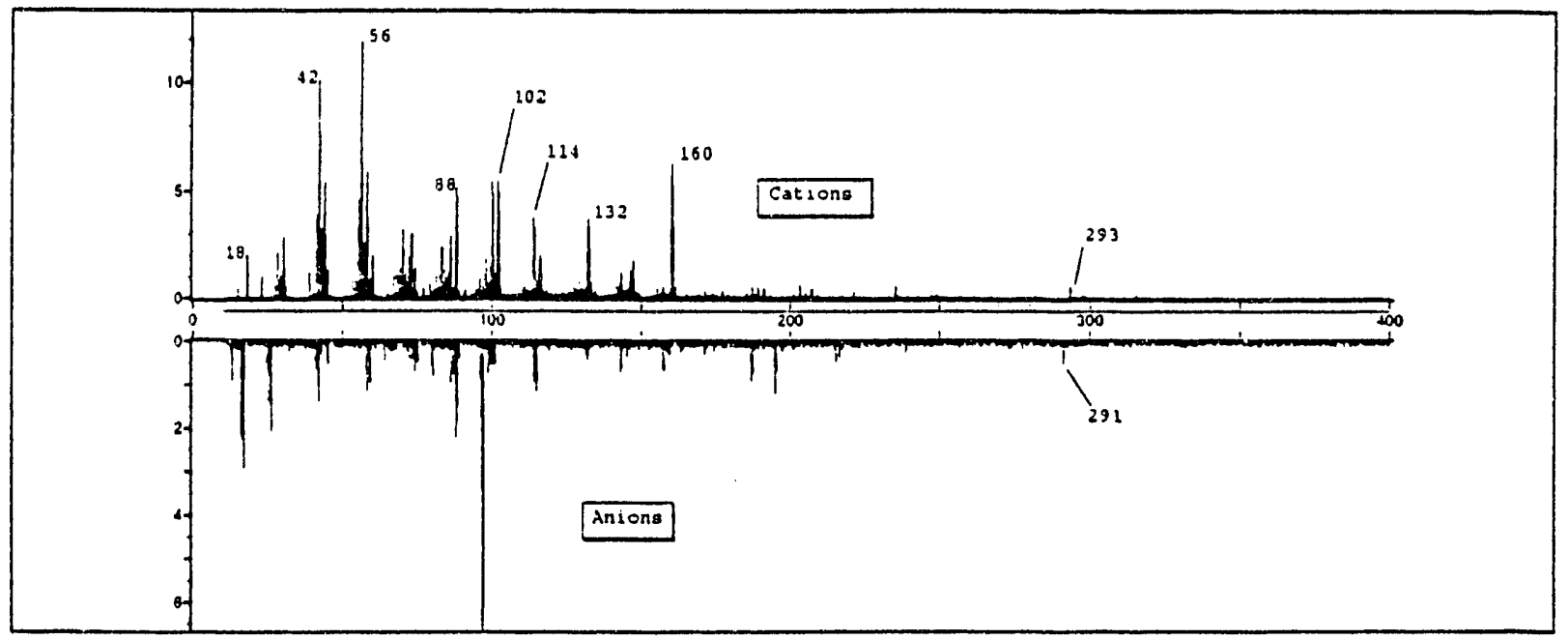

Figure 5. Positive ion (top) and negative ion (bottom) spectra of EDTA powder, which was adhered to the target planchette using double-sided tape.

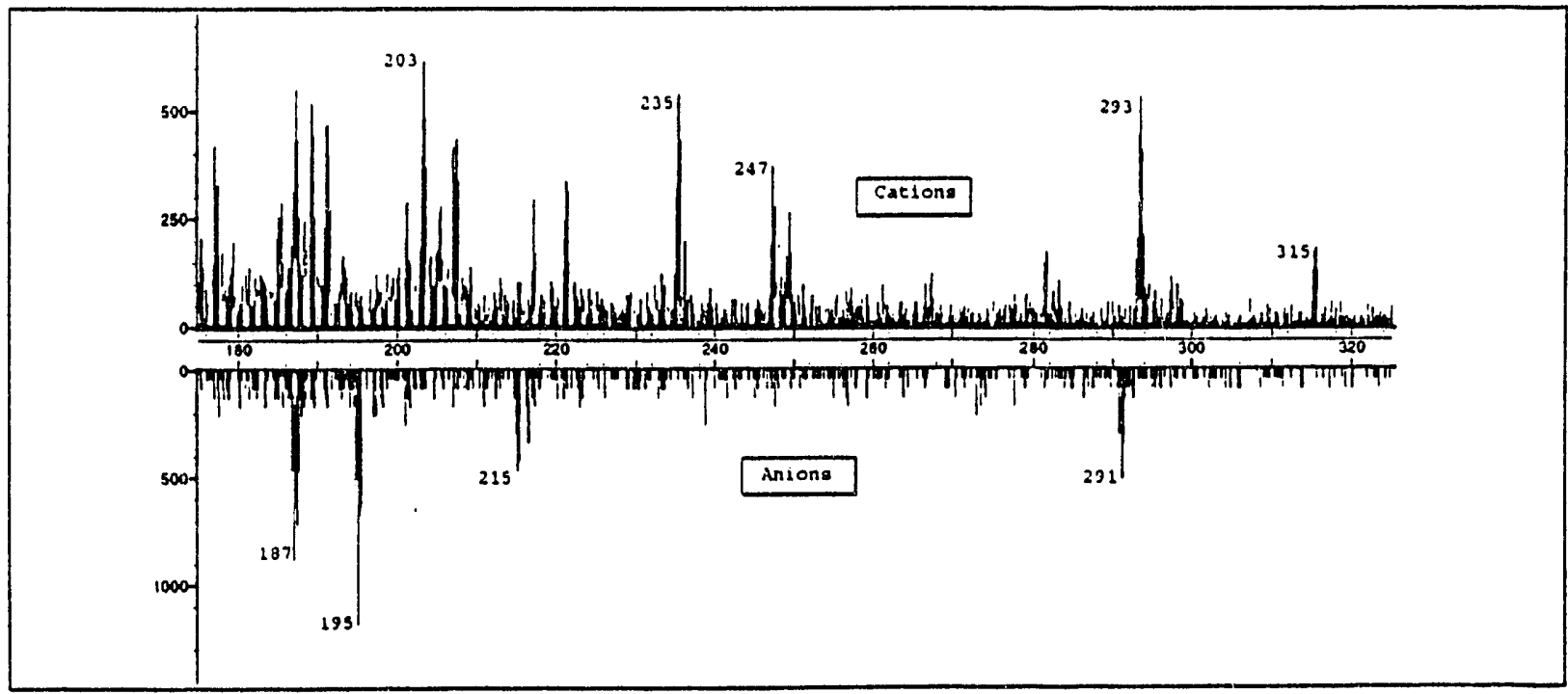

Figure 6. High mass expansion of positive ion (top) and negative ion (bottom) spectra of EDTA powder, which was adhered to the target planchette using double-sided tape. 
be possible to identify one or several of these ions as indicators for the presence of EDTA in the environment. Generally, the higher mass ions are interpreted in terms of small molecule eliminations from, or simple fragmentations of the $[\mathrm{M}+\mathrm{H}]^{+}$and $[\mathrm{M}-\mathrm{H}]^{-}$ions (see Table 1).

The interpretation of ions observed at $\mathrm{m} / \mathrm{z} 114^{+}, 102^{+}, 100^{+}, 97^{\circ}$, and $88^{+}$is not straightforward based on the structure of EDTA. The observation that the cations occur at even mass indicates that these ions likely contain one nitrogen atom. These ions are speculated to be highly condensed, perhaps having unsaturated morpholine-type structures (see Figure 7). $\underline{\mathrm{M} / \mathrm{z}} 97^{-}$is by far the most abundant ion in the anion spectrum, which can be unequivocally attributed to EDTA. The structure of this ion is presently unknown (two proposals are presented in Figure 7), but the abundance of this ion makes it an attractive candidate for a marker ion for EDTA in environmental analyses. Lower mass cations are usually observed at even masses, indicating the presence of a single nitrogen atom

Table 1. Explanation of ions observed in SIM spectra of EDTA powder.

\begin{tabular}{|c|c|c|c|}
\hline \multicolumn{2}{|r|}{ Cations } & \multicolumn{2}{|r|}{ Anions } \\
\hline $\mathrm{m} / \mathrm{z}$ & Assignment & $\mathrm{m} / \mathrm{z}$ & Assignment \\
\hline $315^{+}$ & {$[\mathrm{M}+\mathrm{Na}]^{+}$} & & \\
\hline $293^{+}$ & {$[\mathrm{M}+\mathrm{H}]^{+}$} & $291^{\circ}$ & {$[\mathrm{M}-\mathrm{H}]^{-}$} \\
\hline $249^{+}$ & $293 \cdot \mathrm{CO}_{2}$ & & \\
\hline $247^{+}$ & $293-\mathrm{H}_{2} \mathrm{CO}_{2}$ & $215^{-}$ & $291-\mathrm{CH}_{3} \mathrm{CO}_{3} \mathrm{H}$ (peracetic acid) \\
\hline $235^{+}$ & $293-\mathrm{H}_{2} \mathrm{C}_{2} \mathrm{O}_{2}$ & $195^{\circ}$ & $\begin{array}{l}\text { sequential losses of } 2\left(\mathrm{H}_{2} \mathrm{O}\right) \text { and } \\
\text { acetic acid from } 291\end{array}$ \\
\hline $203^{+}$ & $247 \cdot \mathrm{CO}_{2}$ & $187^{\circ}$ & $\begin{array}{l}\text { sequential losses of } \mathrm{H}_{2} \mathrm{O}, \mathrm{CO}_{2} \\
\text { and ketene from } 291\end{array}$ \\
\hline $160^{+}$ & see Figure 7 & & \\
\hline $146^{+}$ & half molecule, see Figure 7 & & \\
\hline $132^{+}$ & see Figure 7 & & \\
\hline $114^{+}$ & see Figure 7 & & \\
\hline $102^{+}$ & see Figure 7 & & \\
\hline $100^{+}$ & see Figure 7 & $97^{-}$ & $\begin{array}{l}\text { base peak in the anion spectra, } \\
\text { see Figure } 7\end{array}$ \\
\hline $88^{+}$ & see Figure 7 & & \\
\hline $70^{+}$ & $\mathrm{C}_{4} \mathrm{H}_{8} \mathrm{~N}^{+}$ & & \\
\hline $56^{+}$ & $\mathrm{C}_{3} \mathrm{H}_{6} \mathrm{~N}^{+}$, see Figure 8 & & \\
\hline $44^{+}$ & $\mathrm{C}_{2} \mathrm{H}_{6} \mathrm{~N}^{+}$, see Figure 8 & & \\
\hline $42^{+}$ & $\mathrm{C}_{2} \mathrm{H}_{4} \mathrm{~N}^{+}$ & & \\
\hline $30^{+}$ & $\mathrm{CH}_{4} \mathrm{~N}^{+}$, see Figure 8 & & \\
\hline $18^{+}$ & $\mathrm{NH}_{4}{ }^{+}$, see Figure 8 & & \\
\hline
\end{tabular}




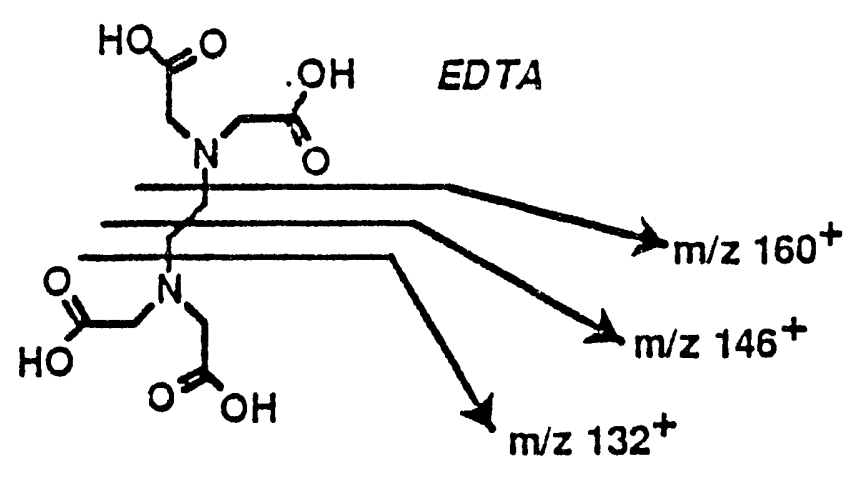<smiles>O=C1C=[NH+]C(=O)OC1</smiles><smiles>C[NH+]1CCOCC1</smiles><smiles>C1COCC[NH+]1</smiles>

$m / 288^{+}$

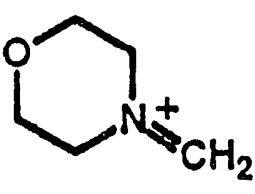

$\mathrm{m} / \mathrm{z} 100^{+}$

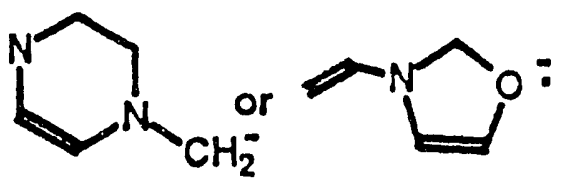

$\mathrm{m} / \mathrm{z} 97^{-}$

Figure 7. Rationalization of ions observed in SIM spectrum of EDTA powder, $\underline{m} / z$ 160-88.

(provided ions are even electron species) (see Figure 8). Normally, ions at lower mass are poor candidates for marker ions because of interferences from the background. These ions may be useful in spite of this problem because the interferences at the even masses is generally much less than interferences at odd masses.

\subsection{EDTA on Stainless Steel}

EDTA was analyzed on stainless steel to determine if small quantities of the chemical produced spectra that were similar to the powder and to assess how the analysis would be affected by a reactive surface. General experimental methodology was to make an aqueous EDTA solution of approximately $0.5 \mathrm{ug} / \mathrm{ul}$ and apply a small volume of the solution directly to the target planchette. The target was allowed to dry and admitted to the MBSA instrument for SIMS analysis.

The initial experiments contained few ions that could be unequivocally attributed to EDTA. This observation was in contrast to other analyses of this type in which MBSA produced abundant ion signal. It was hypothesized that the reason why so little was observed was that EDTA was binding to the steel surface so strongly that sputtering was difficult or impossible. To increase the volatility of the EDTA and to reduce the ability of the molecule to bind to the steel, the pH of the sample solutions was controlled. EDTA can exist in ionic states varying from a tetraanion to a dication, depending on the $\mathrm{pH}$ (see Table 2). Generally, the more anionic forms will bind more strongly to metals than will the neutral or cationic forms. If the MBSA analysis was failing because 


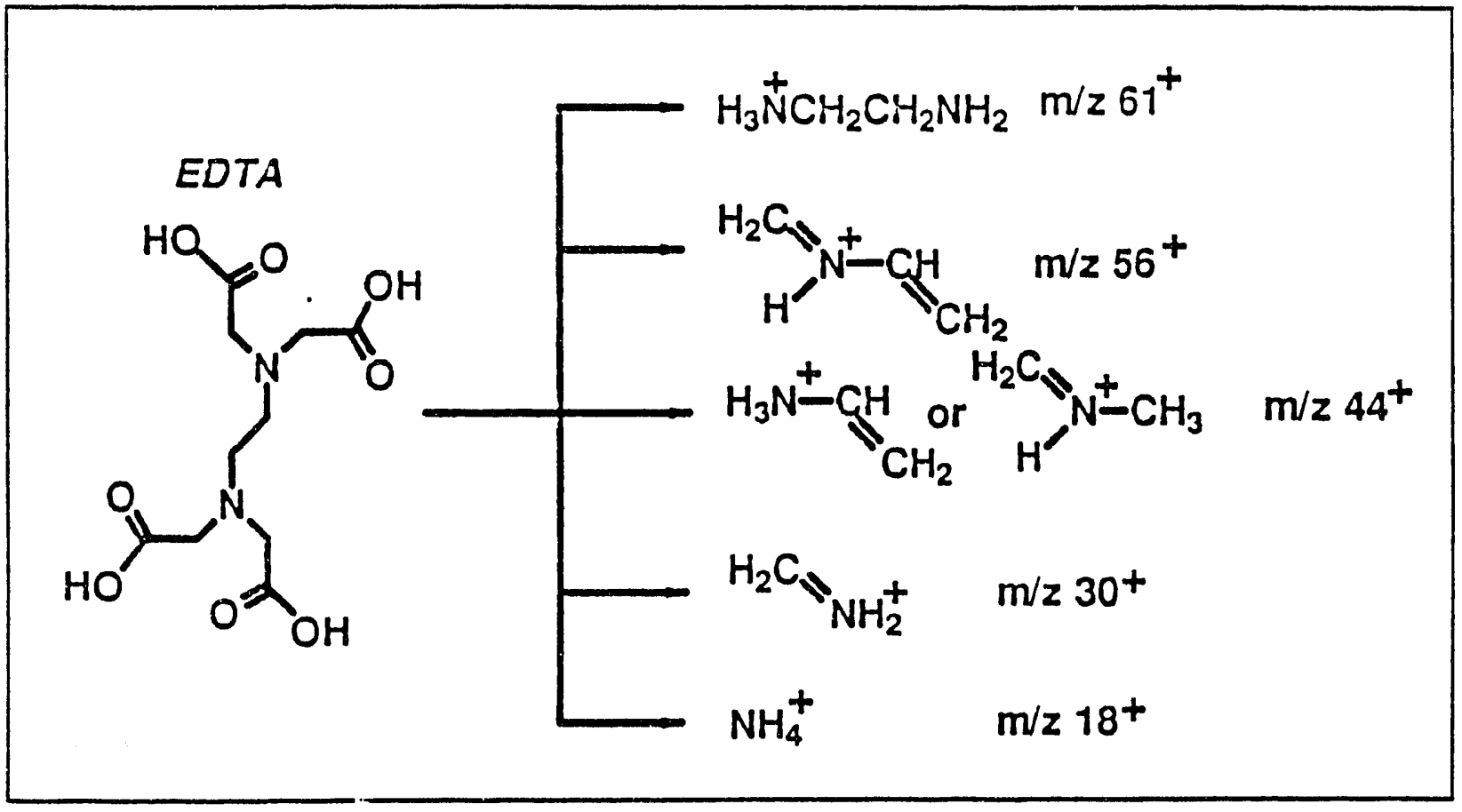

Figure 8. Rationalization of ions observed in SIM spectrum of EDTA powder, $\underline{\mathrm{m} / \mathrm{z}}$ 61-18.

Table 2. Ionic form of EDTA as a function of $\mathrm{pH}$.

\begin{tabular}{|c|c|c|}
\hline & & \\
\hline & & \\
\hline & & \\
\hline & & \\
\hline & & \\
\hline & & \\
\hline & & \\
\hline & & \\
\hline & & \\
\hline & & \\
\hline & & \\
\hline & & \\
\hline & $2.0-2.7$ & $\mathrm{H}_{3} \mathrm{Y}^{-}$ \\
\hline & $2.7-6.6$ & $\mathrm{H}_{2} \mathrm{Y}^{-2}$ \\
\hline & $6.6-10.2$ & $H Y^{-3}$ \\
\hline & & $Y^{-4}$ \\
\hline & Approximate $\mathrm{pH}$ range & Major ionic form \\
\hline & $<0.0$ & $\mathrm{H}_{6} \mathrm{Y}^{+2}$ \\
\hline & $0.0-1.5$ & $\mathrm{H}_{5} \mathrm{Y}^{+}$ \\
\hline & $1.5-2.0$ & $\mathrm{H}_{4} \mathrm{Y}^{\circ}$ \\
\hline & & $\mathrm{H}_{3} \mathbf{I}$ \\
\hline & & \\
\hline & & \\
\hline & $>10.2$ & $Y^{-4}$ \\
\hline
\end{tabular}

the EDTA was binding to the steel surface, then the problem could perhaps be ameliorated by decreasing the tendency of the EDTA to bind to metals, which could be achieved by applying the EDTA to the steel in neutral or cationic forms.

When acidified solutions of EDTA were applied to steel planchettes and then analyzed, abundant, low mass, even electron ions $\left(\underline{\mathrm{m} / \mathrm{z}} 61^{+}, 56^{+}, 44^{+}, 30^{+}, 18^{+}\right)$could be clearly observed in the mass spectra (see spectrum in Figure 9 and ions in Figure 8). These ions could be seen above the background at $\mathrm{pH} 1.0\left(\mathrm{H}_{5} \mathrm{Y}^{+}\right), 1.8\left(\mathrm{H}_{4} \mathrm{Y}^{\circ}\right), 2.3\left(\mathrm{H}_{3} \mathrm{Y}^{\circ}\right)$, and $4.1\left(\mathrm{H}_{2} \mathrm{Y}^{-2}\right)$ and, in general, were most abundant at the lower $\mathrm{pH}$ values. At higher $\mathrm{pH}$ values $(10.1,11.8)$, these same ions were not observable above the background (see Figure 10). These experiments indicate that observation of ions derived from EDTA may be dependent upon the species of EDTA that was applied to the 


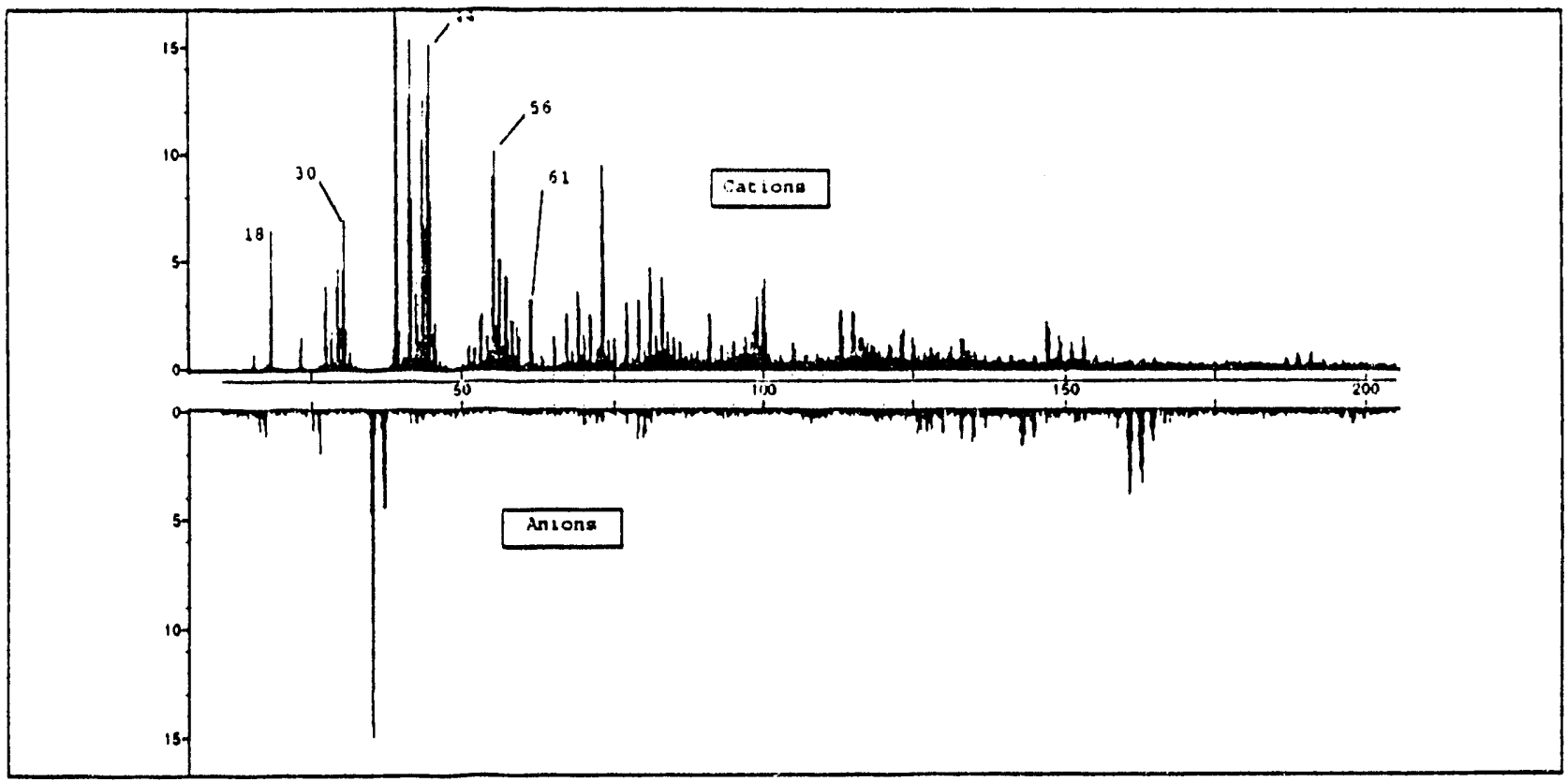

Figure 9. Cation (top) and anion (bottom) SIM spectra of EDTA on stainless steel; EDTA applied as a $\mathrm{pH}=1$ solution.

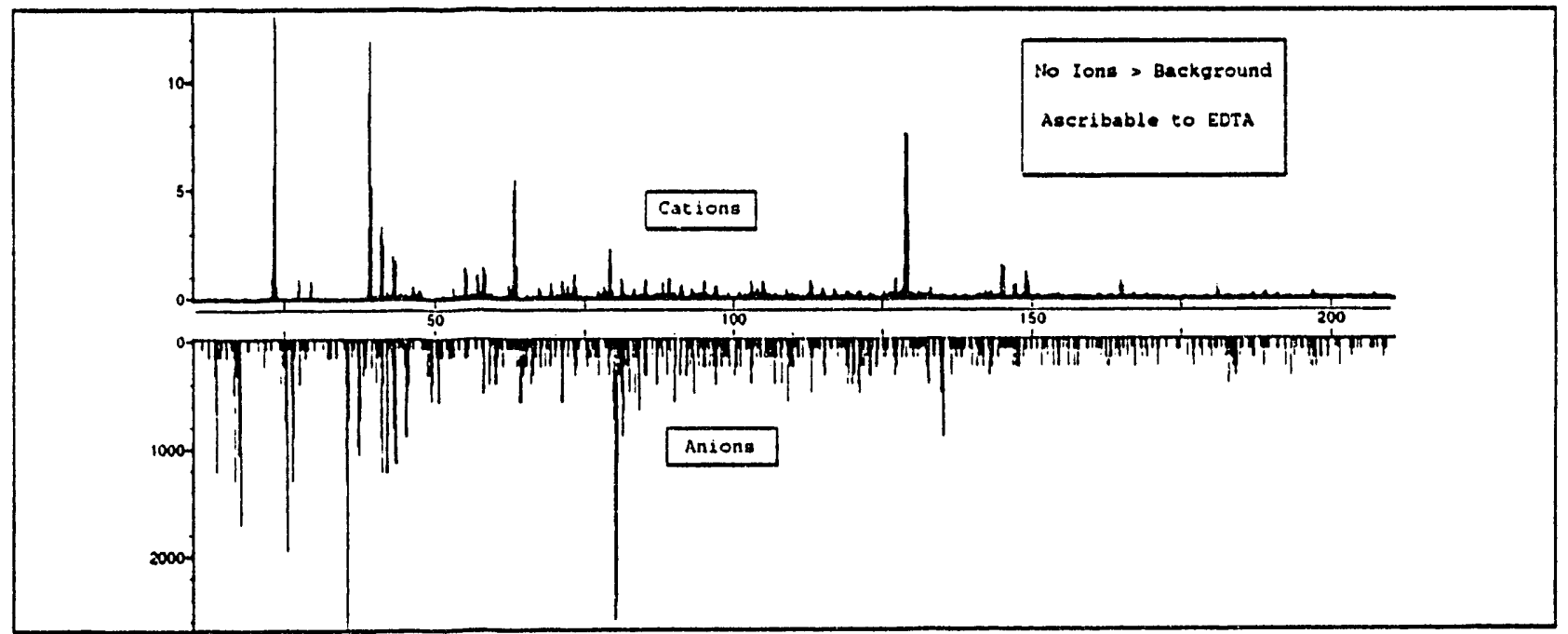

Figure 10. SIM spectrum of EDTA applied to stainless steel as a $\mathrm{pH}=10$ solution.

target; alternatively, the acid solutions may protonate the surface of the steel target, thereby providing a supply of protons necessary for the formation of the low mass ions described in Figure 8.

\subsection{EDTA on Rocks and Soil}

It was difficult to observe ions derived from pH-neutral, EDTA solutions that had been spiked onto small rocks and then admitted to the MBSA instrument for analysis. SIM spectra of rocks that had been spiked with acidified EDTA solutions, on the other hand, contained ions at $\mathrm{m} / \mathrm{z} 61^{+}, 44^{+}$, $30^{+}$, and $97^{\circ}$, which are attributed to EDTA, and are not observed with any abundance in the benchmark (i.e., unspiked) spectrum of the same rock (see Figure 11). 


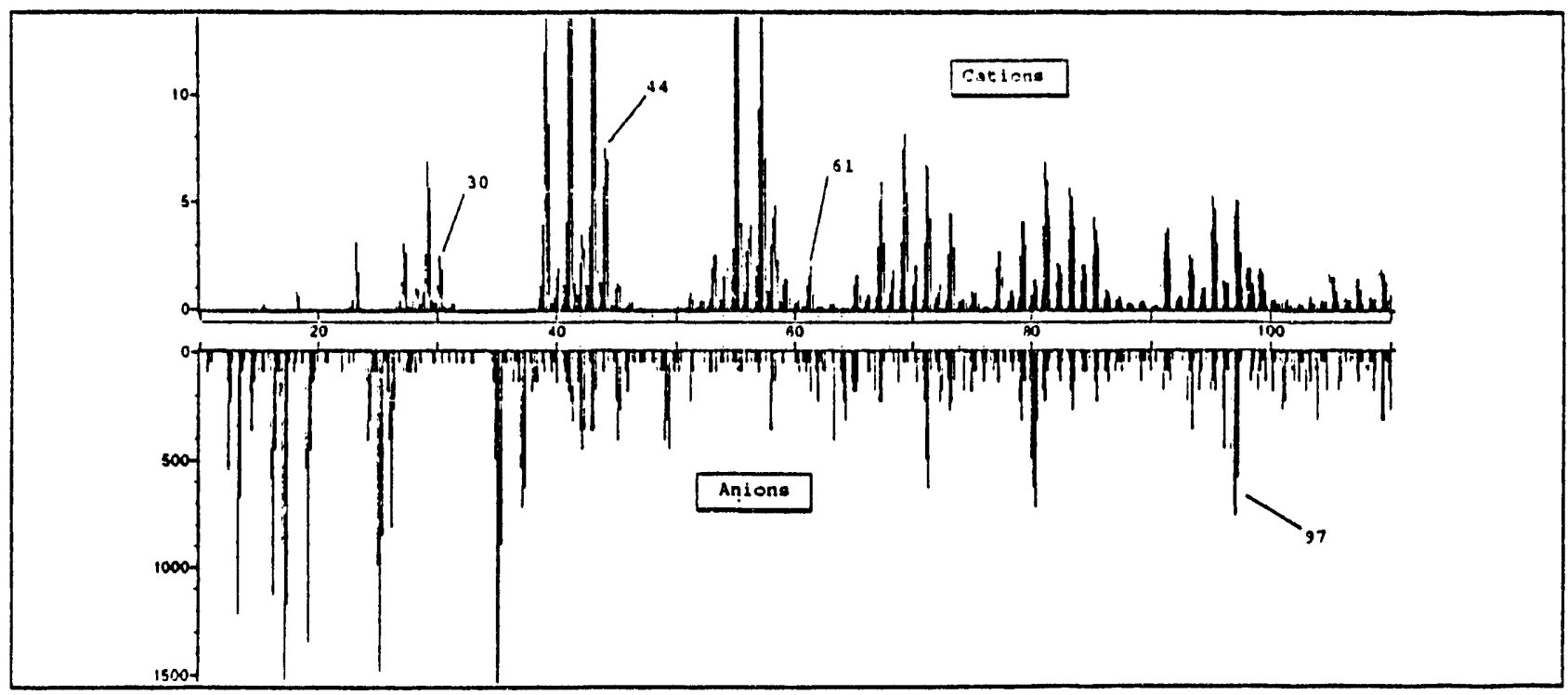

Figure 11. $1100 \mathrm{ng}$ of EDTA solution ( $\mathrm{pH}=1.0)$ spiked onto a small rock (calcium fluorite).

An EDTA solution was spiked onto soil, the soil was subsequently pressed onto double-sided tape, attached to a target planchette and then admitted to the MBSA instrument for analysis. No ions ascribable to EDTA could be observed in the resultant mass spectrum. The failure to detect EDTA in this experiment is probably caused by the EDTA solution absorbing into the soil sample; the result underscores the fact that MBSA is a surface analysis technique. Alternative strategies for detecting EDTA in soil samples may have to be conceived.

\subsection{Disodium EDTA and Disodium Magnesium EDTA}

The disodium salt of EDTA was analyzed to assess the effect that sodium would have on the MBSA analysis. The disodium salt was analyzed as a powder stuck onto double sided tape and as a solution residue applied to stainless steel and glass. The presence of large quantities of sodium on the surface of the sample has a dramatic impact on the appearance of the SIM spectrum (an example is shown in Figure 12). The "low-mass, even electron" cations characteristic of the acidic forms of EDTA are no longer observable; instead, the low mass region of the positive ion spectrum is dominated by $\mathrm{m} / \mathrm{z} 23^{+}\left(\mathrm{Na}^{+}\right)$and $\mathrm{m} / \mathrm{z} 63^{+}\left[(\mathrm{NaOH}) \mathrm{Na}^{+}\right]$. A relatively abundant ion (approximately 5 to $20 \%$ ) is observed at $\mathrm{m} / \mathrm{z} 72^{+}$, which certainly originates from the disodium EDTA. The structure of this ion is unknown: one possibility is shown in Figure 13. $\mathrm{A} \mathrm{C}_{3} \mathrm{H}_{6} \mathrm{NO}^{+}$isomer seems reasonable, but it is not clear why this ion is not observed in the SIM spectrum of the EDTA tetraacid. One explanation is that the sodium may be catalyzing the formation of this ion. As in the case of the tetraacid, ions corresponding to simple cleavage reactions are observed at $\mathrm{m} / \mathrm{z} 132^{+}$and $146^{+}$(see Figure 7), and the ion at $\mathrm{m} / \mathrm{z} 154^{+}$is in all likelihood the natiated form of the $\mathrm{m} / \mathrm{z} 132^{+}$ion. Low abundance ions are observed at $\mathrm{m} / \mathrm{z} 200^{+}$and $255^{+}$, and speculative ion structures are shown in Figure 13. None of the other cations observed in the spectra have been satisfactorily interpreted. No significant anions were observed.

The disodium magnesium salt of EDTA was also analyzed. The SIM spectra acquired were nearly identical to the disodium EDTA spectra in that the salient ions were $\mathrm{m} / \mathrm{z} 23^{+}, 63^{+}$, and $72^{+}$. 


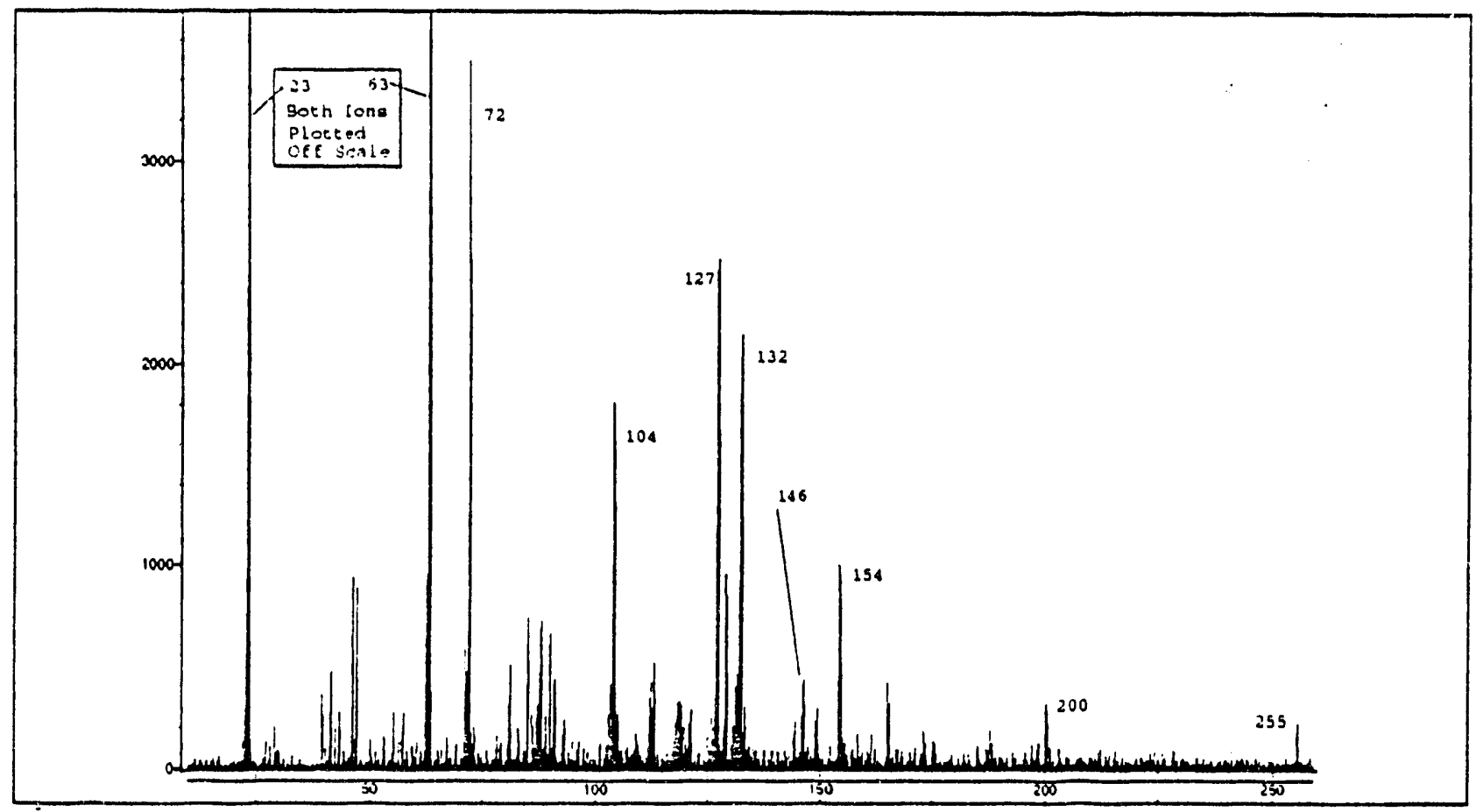

Figure 12. SIM spectrum (cation only) of disodium EDTA powder, which was adhered to a target planchette using double-sided tape.

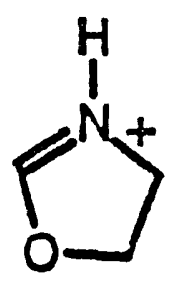

$m / 272^{+}$

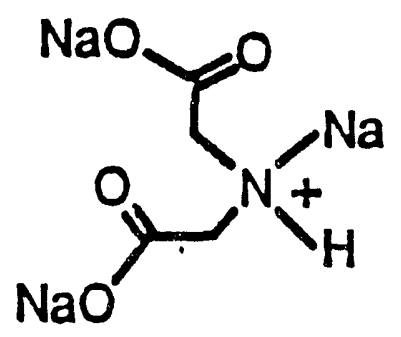

$\mathrm{m} / \mathrm{z} 200^{+}$

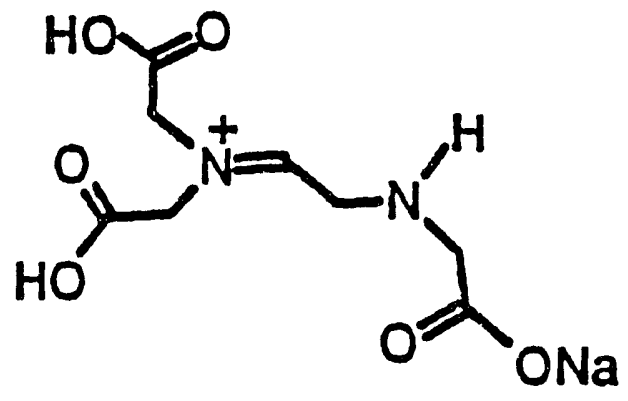

$\mathrm{m} / \mathrm{z} 255^{+}$

Figure 13. Speculative structures for $\underline{\mathrm{m} / \mathrm{z}} 72^{+}, 200^{+} 255^{+}$observed in the SIM spectrum of disodium EDTA.

Lower abundance ions at $\mathrm{m} / \mathrm{z} 88^{+}, 104^{+}, 127^{+}, 129^{+}, 132^{+}$, and $154^{+}$were also observed. No obvious evidence for magnesium was observable.

\subsection{EDTA with Cobalt(II) and Lead(II) on Stainless Steel}

Target planchettes were made with EDTA and cobalt to see if EDTA-cobalt complexes could be observed directly on stainless steel using MBSA. The planchettes were made by spiking small quantities of EDTA and $\mathrm{CoCl}_{2}$ solutions onto the targets and then allowing them to air dry. The 
target planchettes were then admitted to the MBSA instrument and analyzed. No ions were observed that could be unequivocally attributed to an EDTA-cobalt complex, and other ions known to arise from EDTA alone were in low abundance. This observation was repeated over a range of $\mathrm{pH}$ values (1 to 11.7), and a over a range of EDTA-cobalt molar ratios (1 to 6). Abundant ions were observed that originated from $\mathrm{CoCl}_{2}$, which served as the source of the cobalt. These ions corresponded to $\mathrm{CoCl}_{2}^{-},\left(\mathrm{CoCl}_{2}\right) \mathrm{Cl}^{-},\left(\mathrm{CoCl}_{2}\right)_{2}^{-}$, and $\left(\mathrm{CoCl}_{2}\right)_{2} \mathrm{Cl}^{-}$; a partial mass spectrum typical of these experiments is shown in Figure 14.

EDTA and lead were investigated in the same manner. The nitrate salt of lead(II) was used to make the targets (as opposed to the $\mathrm{Cl}^{-}$in the case of cobalt). When the EDTA-lead targets were analyzed, a higher mass ion cluster was observed in the anion spectrum (partial SIM spectrum is shown in Figure 15), with the most abundant ion at $\mathrm{m} / \mathrm{z} 393^{\circ}$. This cluster was approximately 4 amu wide, from $\mathrm{m} / \mathrm{z} 391$ to 394 (inclusive), and the isotope distribution did not correspond well with the distribution corresponding to a single lead. When $\mathrm{Pb}\left(\mathrm{NO}_{3}\right)_{2}$ was analyzed in the absence of EDTA, an ion ciuster was observed at approxirnately the same mass, but the most abundant ion in the cluster was $\mathrm{m} / \mathrm{z} 394^{\circ}$, and the cluster was only $3 \mathrm{amu}$ wide ( $\mathrm{m} / \mathrm{z} 392^{\circ}$ to $394^{\circ}$, inclusive). Furthermore, the isotope distribution of the ions in the cluster observed in the latter experiment corresponded very well with the distribution predicted for an ion containing a single lead atom.

These ions in the EDTA-lead experiment are cautiously interpreted in terms of overlapping lead isotope clusters: a cluster at $\mathrm{m} / \mathrm{z} 392^{\circ}-394^{\circ}$ arising from $\mathrm{Pb}\left(\mathrm{NO}_{3}\right)_{3}{ }^{\circ}$, and a cluster at $\mathrm{m} / \mathrm{z} 391^{\circ}-393^{-}$, which corresponds to the sequentia' losses of $\mathrm{H}_{2} \mathrm{O}$, ketene $\left(\mathrm{CH}_{2} \mathrm{CO}\right)$ and $\mathrm{CO}_{2}$ from [Pb - EDTA $\left.\mathrm{H}^{-}\right]$( $\mathrm{m} / \mathrm{z} 497^{\circ}$, not observed). This loss is also observed in the SIM spectrum of the EDTA tetraacid.

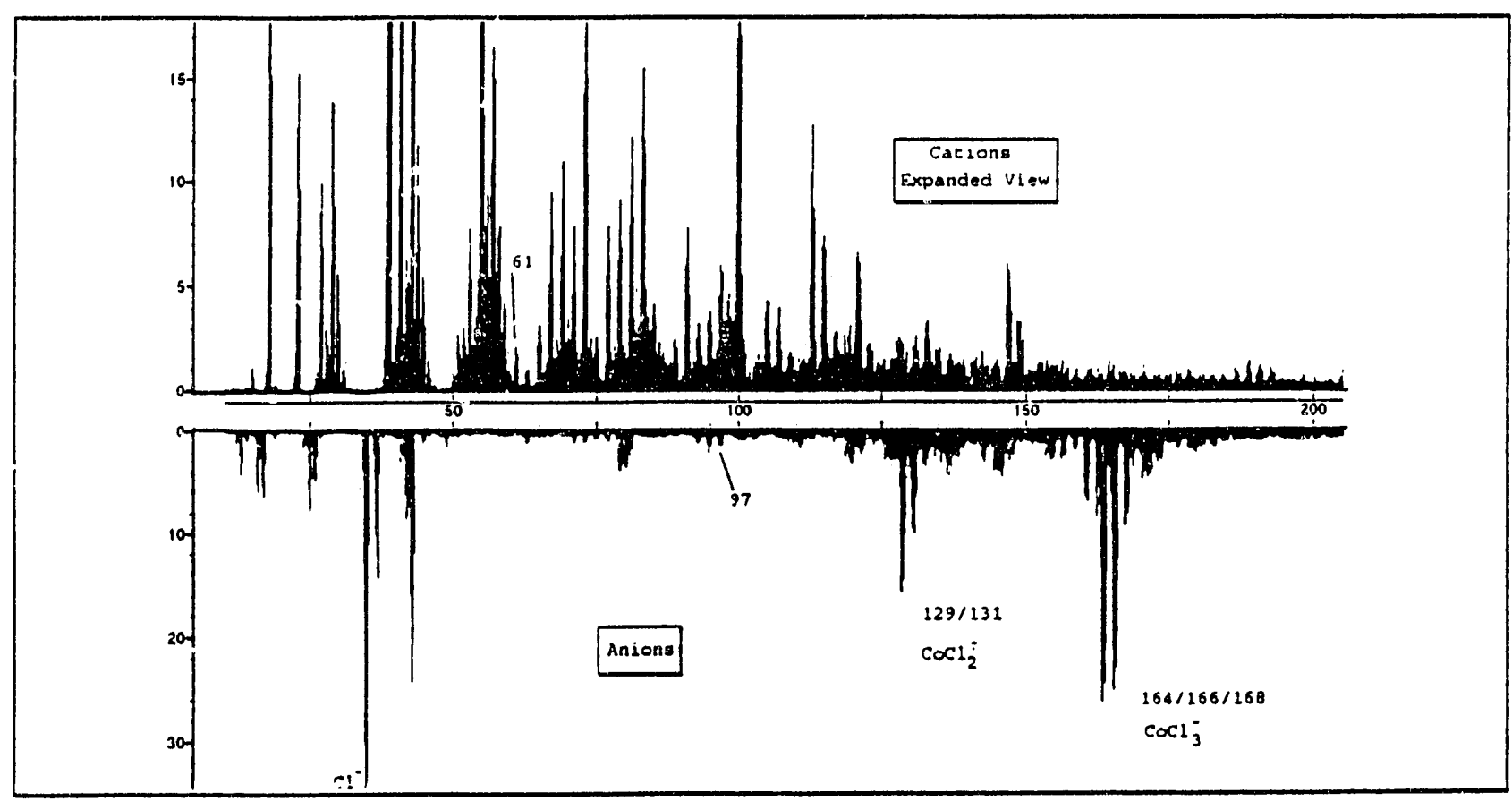

Figure 14. Partial cation (top) and anion (bottom) SIM spectrum of cobalt(II) together with EDTA (deposited as a $\mathrm{pH}=1.8\left(\mathrm{Y}^{\circ}\right)$ solution); crbalt(II) was deposited as a $\mathrm{CoCl}_{2}$ solution, and cobalt(II) is in a 3:1 molar excess relative to EDTA. 


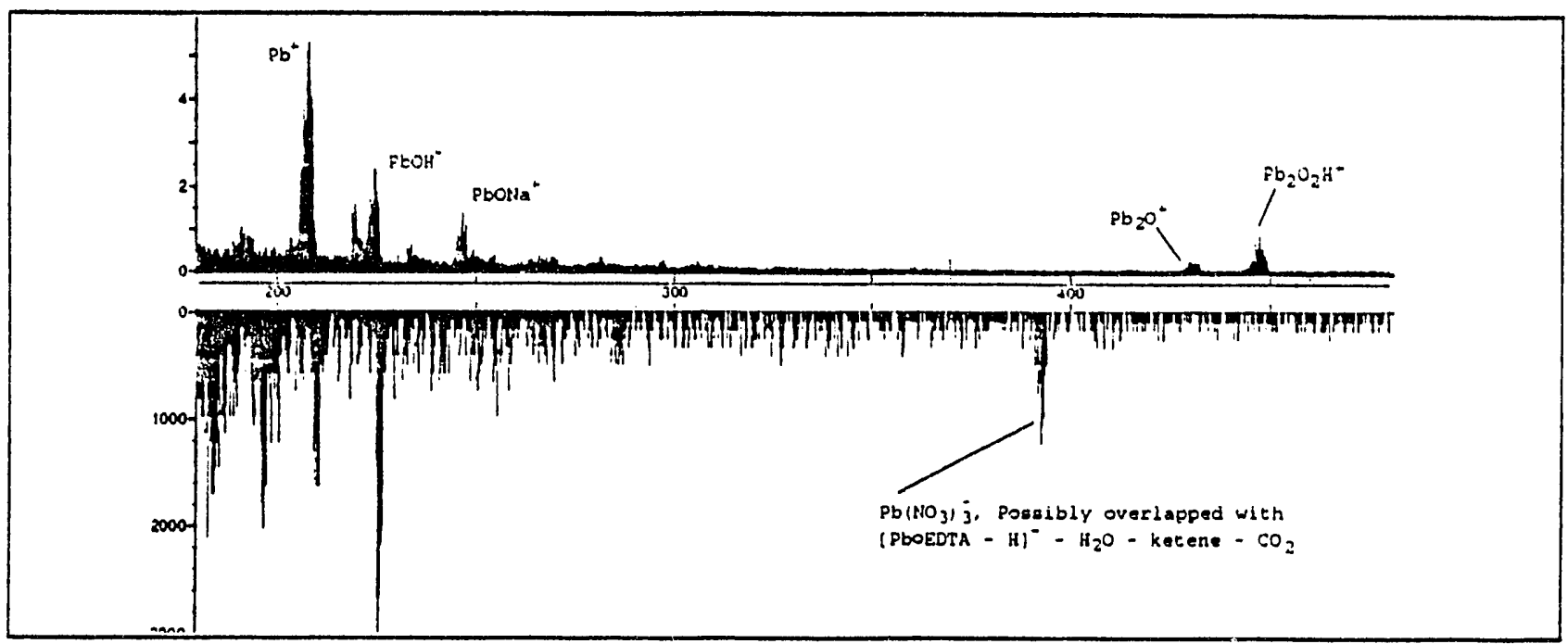

Figure 15. Partial cation (top) and anion (bottom) SIM spectrum of EDTA-lead on stainless steel.

Lead routinely gives rise to other ions in the SIM spectrum; salient ions observed in the EDTA-lead experiment are assigned in Table 3.

Table 3. Assignment of ions observed in the EDTA-lead SIM spectra.

\begin{aligned} & \hline $\mathrm{m} / \mathrm{z} \multicolumn{1}{c}{$ Assignment } \\ & \hline $449^{+}-445^{+} \mathrm{Pb}_{2} \mathrm{O}_{2} \mathrm{H}^{+} \\ & 432^{+}-428^{+} \mathrm{Pb}_{2}{ }^{+} \\ & 394^{-}-392^{-} \mathrm{Pb}\left(\mathrm{NO}_{3}\right)^{-} \\ & 393^{-}-301^{-} {\left[\mathrm{Pb}-\mathrm{EDTA}^{-} \mathrm{H}\right]^{-}-\mathrm{H}_{2} \mathrm{O}-$ ketene $\left(\mathrm{CH}_{2} \mathrm{CO}\right)-\mathrm{CO}_{2} } \\ & 225^{+}-223^{+} \mathrm{PbOH}^{+} \\ & 208^{+}-206^{+} \mathrm{Pb}^{+} \\ &$\hline\end{aligned}

\subsection{EDTA on Teflon and Polyethylene}

EDTA was analyzed on teflon and polyethylene to observe intact EDTA molecular ions and intact EDTA-metal complex ions. It is hypothesized that the polymer surfaces would be less reactive than steel or rock and, hence, facilitate the production of intact molecular ions. The samples were prepared by sticking a small piece (approximately $2 \times 2 \mathrm{~mm}$ ) of teflon or polyethylene to a target planchette (using double-sided tape), spiking the polymer with analyte solutions, allowing the targets to dry, and admitting the targets to the MBSA instrument for analysis. Analyte solutions that were studied were EDTA at a variety of $\mathrm{pH}$ values, and $\mathrm{CoCl}_{2}$. When teflon samples were treated with the lower $\mathrm{pHI}$ EDTA solutions $(\mathrm{pH}=1.0,1.8,2.3)$, the EDTA low mass signature ions $\left(\mathrm{m} / \mathrm{z}^{2} 61^{+}, 56^{+}\right.$, $44^{+}, 30^{+}, 18^{+}$) (see Figure 8 ) could be observed above the background. On a relative basis, these ions were not as abundant as in the stainless steel analyses because of the very intense tefion ions in the spectra. At higher $\mathrm{pH}$ values, the low mass ions became difficult to observe. Instead, a low abundance ion at $\underline{\mathrm{m} / \mathrm{z}} 235^{+}$was observed above the background, which may be attributable to EDTA. A reasonable structure for this ion is proposed in Figure 16. 


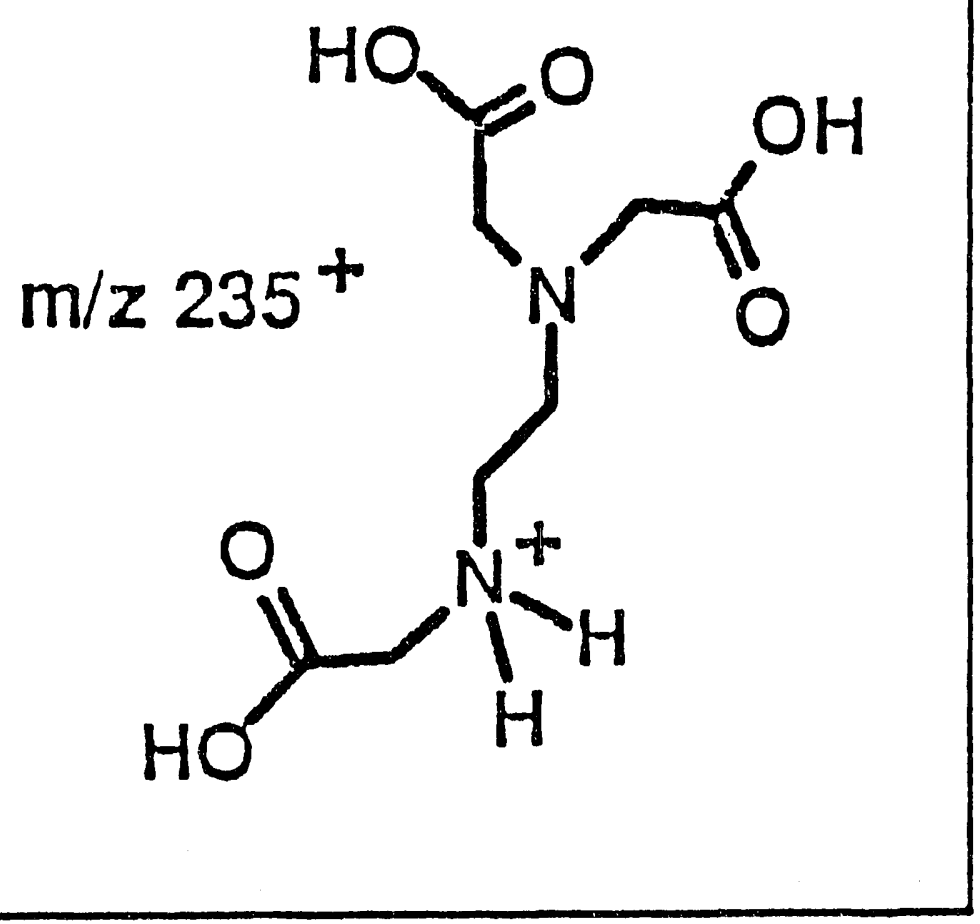

Figure 16. Proposed structure for $\underline{m} / \mathrm{z} 235^{+}$observed in the SIM spectrum of EDTA on teflon.

When the teflon samples were treated with EDTA and cobalt, no ions corresponding to either analyte were observed. In addition, abundant analyte ions were not detected when using polyethylene as a sample.

Teflon and polyethylene are poor sample materials for the detection of EDTA. It is speculated that this is due to the ease of formation of abundant organic ions from the surface of these polymers, which has the effect of suppressing the formation of the analyte ions. 


\section{TBP STUDIES}

TBP was studied on a variety of different substrates to understand its fragmentation chemistry under SIMS bombardment and to identify characteristic ions that may be useful for detection purposes.

\subsection{TBP on Stainless Steel}

Initial experiments were conducted by applying TBP neat to a stainless steel planchette and then admitting this target to the MBSA instrument for analysis. These experiments were performed to identify those ions characteristic of TBP. Abundant anions and cations were observed (see Figure 17) that were attributed to TBP, and a large $\underline{\mathrm{m} / \mathrm{z}} 23^{+}$ion was observed that corresponds to $\mathrm{Na}^{+}$. The presence of sodium in the experiment had a dramatic effect on the appearance of the cation spectrum; all of the higher mass cations observed $(<\underline{m / z} 125)$ are best interpreted in terms of sodium attachment ions (see Table 4). In contrast, none of the peaks in the anion spectrum could be interpreted as containing sodium. The highest mass ion in the anion spectrum corresponds to the loss of $\mathrm{C}_{4} \mathrm{H}_{\mathrm{q}}, \mathrm{m} / \mathrm{z}$ 209. Lower abundance ions between $209^{\circ}$ and $97^{-}$likely arise via the loss of small, neutral molecules. Proposed structures for selected ions are presented in Figure 18.

TBP was also analyzed as a dilute solution on a stainless steel planchette (the solution being allowed to dry before analysis). The SIM spectra that were obtained were similar to the spectra of the neat TBP but not identical. $[\mathrm{M}+\mathrm{Na}]^{+}$and $[\mathrm{M}+\mathrm{H}]^{+}$were more abundant in this latter experiment, but the wide variety of anions observed in the analysis of the neat TBP had all but disappeared. It is presumed that these effects are due to the bulk liquid, but they are not understood at this time.

Table 4. Assignment of ions observed in the SIM spectra of neat TBP on stainler- steel.

\begin{tabular}{|c|c|c|c|}
\hline $\mathrm{m} / \mathrm{z}$ & Cation assignment & $\mathrm{m} / \mathrm{z}$ & Anion assignment \\
\hline $255^{+}$ & $\left(\mathrm{C}_{4} \mathrm{H}_{9} \mathrm{O}\right)_{2}-\mathrm{P}^{+}-(\mathrm{ONa})_{2}$ & $209^{-}$ & $\left(\mathrm{C}_{4} \mathrm{H}_{9} \mathrm{O}\right)_{2}-\mathrm{PO}_{2}^{-}$ \\
\hline $221^{+}$ & $\left(\mathrm{C}_{4} \mathrm{H}_{9} \mathrm{O}\right)-\mathrm{P}^{+}-(\mathrm{ONa})_{3}$ & $181^{-}$ & $209^{-}-\mathrm{C}_{2} \mathrm{H}_{4}$ \\
\hline $199^{+}$ & $\mathrm{C}_{4} \mathrm{H}_{9} \mathrm{O}-\mathrm{P}^{+}-(\mathrm{OH})(\mathrm{ONa})_{2}$ & $179^{-}$ & $209^{-}-\mathrm{C}_{-2} \mathrm{H}_{6}$ \\
\hline $165^{+}$ & $(\mathrm{NaO})_{3}-\mathrm{P}^{+}-\mathrm{OH}$ & $165^{-}$ & $209^{-}-\mathrm{C}_{3} \mathrm{H}_{8}$ \\
\hline $125^{+}$ & $\mathrm{C}_{2} \mathrm{H}_{6} \mathrm{PO}_{4}^{+}$isomer & $153^{-}$ & $209^{-}-\mathrm{C}_{4} \mathrm{H}_{8}$ \\
\hline $109^{+}$ & $\mathrm{C}_{2} \mathrm{H}_{6} \mathrm{PO}_{3}^{+}$isomer & $149^{-}$ & $209^{-}-\mathrm{C}_{3} \mathrm{H}_{8} \mathrm{O}$ \\
\hline \multirow[t]{5}{*}{$99^{+}$} & $\mathrm{P}(\mathrm{OH})_{4}^{+}$ & $137^{-}$ & $209^{-}-\mathrm{C}_{4} \mathrm{H}_{8} \mathrm{O}$ \\
\hline & & $123^{-}$ & $179^{-}-\mathrm{C}_{4} \mathrm{H}_{8}$ \\
\hline & & $97^{\circ}$ & $\mathrm{H}_{2} \mathrm{PO}_{4}^{-}$ \\
\hline & & $79^{-}$ & $\mathrm{PO}_{3}{ }^{\circ}$ \\
\hline & & $63^{\circ}$ & $\mathrm{PO}_{2}{ }^{-}$ \\
\hline
\end{tabular}




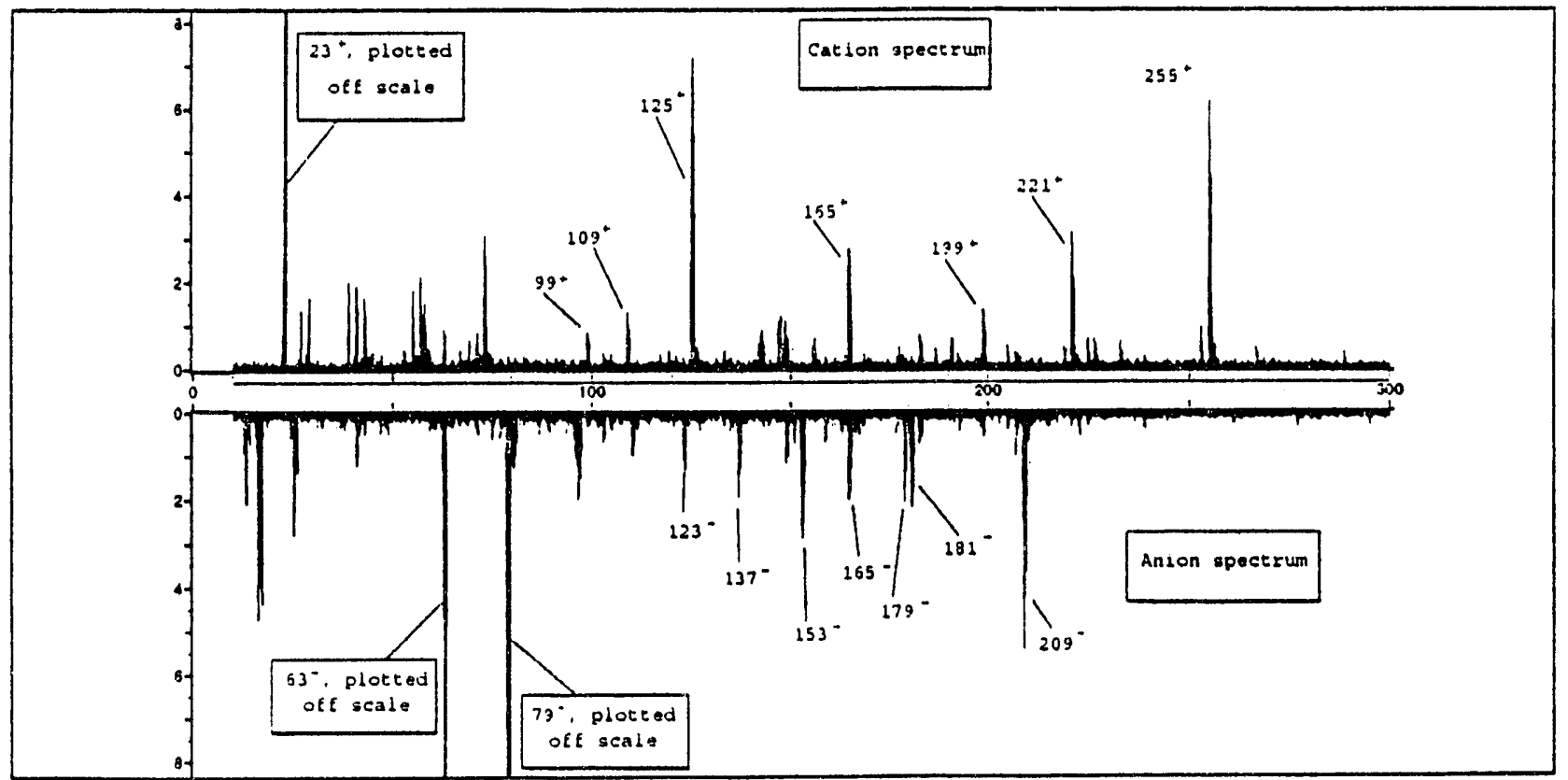

Figure 17. Cation (top) and anion (bottom) SIM spectrum of TBP on stainless steel.<smiles>CCCCCOP(=O)(OC)OCCO</smiles>

TBP<smiles>O[P+]1(O)OCCO1</smiles>

$\mathrm{m} / \mathrm{z} 125^{+}$

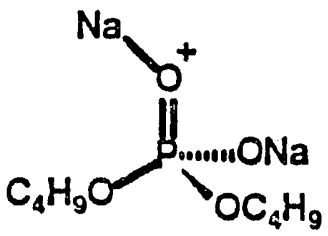

$\mathrm{m} / 2255^{+}$

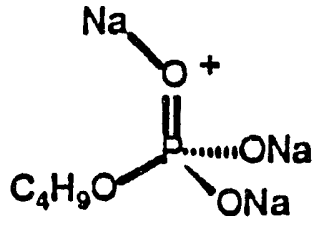

$\mathrm{m} / \mathrm{z} 221^{+}$<smiles></smiles>

$\mathrm{m} / \mathrm{z} 199^{+}$<smiles>O=C([O-])OCCCCCCCO</smiles>

$m / 2209^{\circ}$<smiles></smiles>

$\mathrm{m} / \mathrm{z} 153^{-}$<smiles>O=P1([O-])OCCO1</smiles>

$\mathrm{m} / \mathrm{z} 123$

Figure 18. Structure of TBP and proposed structures of selected ions listed in Table 4.

\subsection{TBP on Rocks: Basalt and Sandstone}

TBP could be readily observed when a basalt chip was spiked with a small volume of a dilute solution and subsequently analyzed. Cation and anion spectra of $250 \mathrm{ng}$ of TBP on basalt are presented in Figure 19, with the background (unspiked) spectra of basalt shown in Figure 20. The cation spectrum did not contain the natiated ions seen in the TBP/stainless steel experiments, and two new ions were observed at $\mathrm{m} / \mathrm{z} 235^{+}$and $217^{+}$, which have thus far resisted explanation. These ions were also observed in the experiments using the parking lot rock (see discussion below). Other 


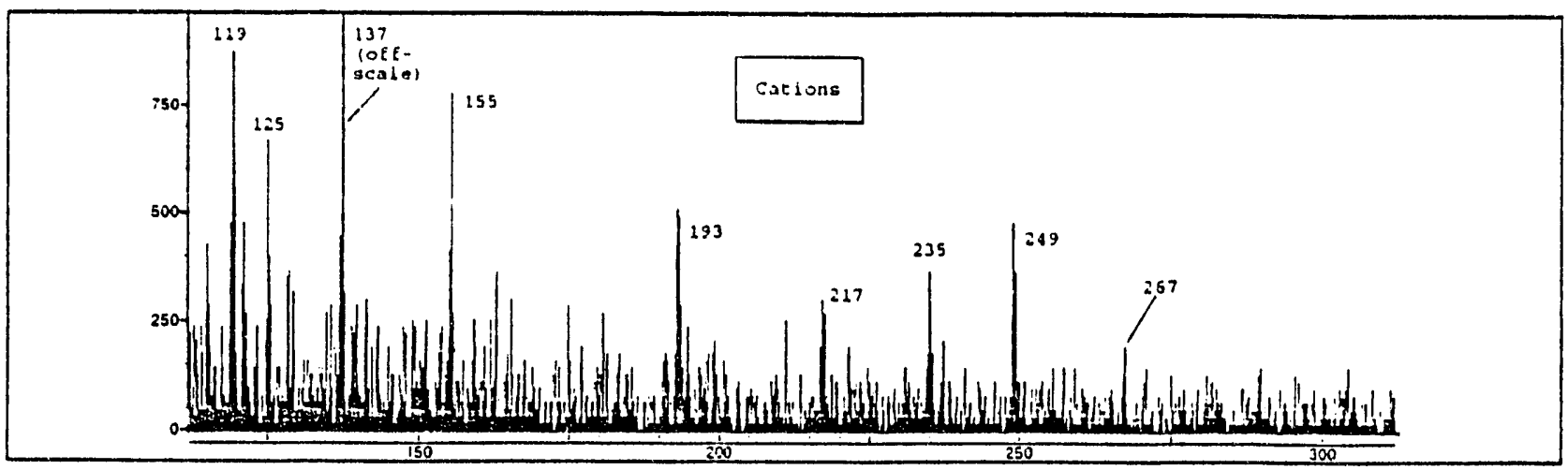

Figure 19. Cation SIM spectrum of $250 \mathrm{ng}$ of TBP on basalt. No significant anions were detected.

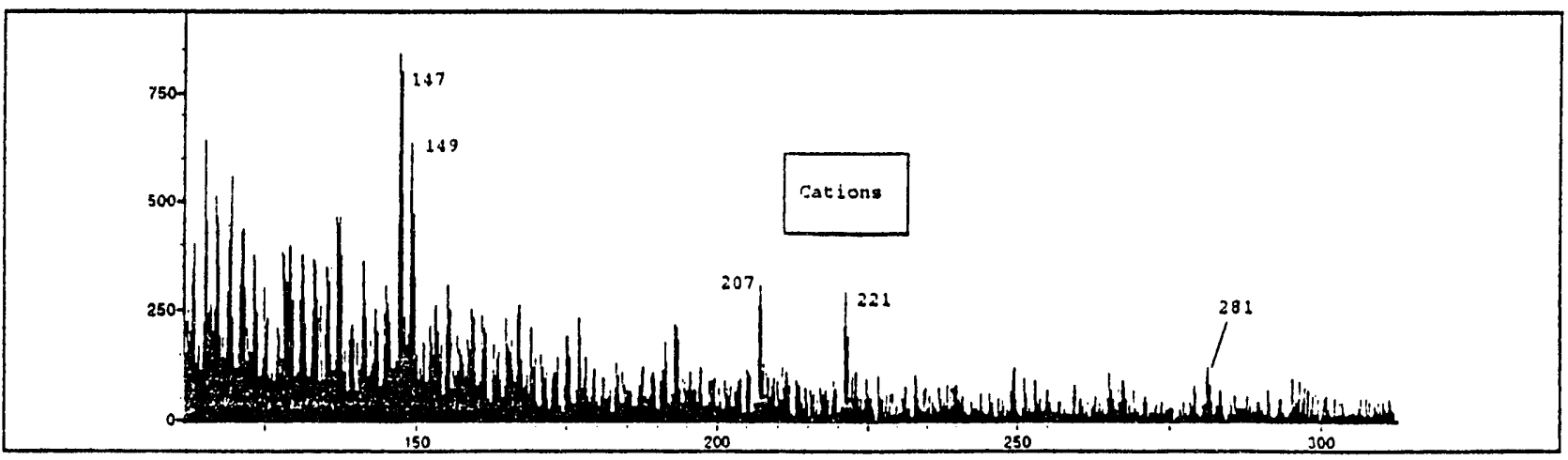

Figure 20. Benchmark cation SIM spectrum of (unspiked) basalt.

cations observed are assigned in Table 5. No anions were detected that could be unequivocally ascribed to TBP; $\mathrm{m} / \mathrm{z} 79^{-}\left(\mathrm{PO}_{3}{ }^{\circ}\right)$ and $63^{\circ}\left(\mathrm{PO}_{2}{ }^{\circ}\right)$ were observed, but these are also seen in the spectrum of unspiked basalt.

TBP could also be readily detected on sandstone, which is a good surface for analysis because the SIM spectral background is low. The cation spectrum was very similar to the spectrum obtained for TBP on basalt, with the notable exception that $\mathrm{m} / \mathrm{z} 235^{+}$and $217^{+}$were absent. The ions present in this spectrum are assigned in Table 6, and the TBP-spiked and benchmark sandstone cation SIM spectra are shown in Figures 21 and 22. As in the case of the basalt, few significant anions were observed.

TBP was also spiked on a small rock that was collected from the INEL Research Center parking lot, and subsequently analyzed. The resultant spectra were very similar to those obtained in the sandstone and basalt experiments, with some minor exceptions. Sufficient sodium was present on the parking lot rock to form $\underline{\mathrm{m} / \mathrm{z} 289^{+}}\left[(\mathrm{M}+\mathrm{Na})^{+}\right] . \mathrm{M} / \mathrm{z} 235^{+}$and $217^{+}$were observed in the spectrum of the spiked parking lot rock: these ions were also observed in the basalt experiment, but were absent in the stainless steel and sandstone experiments. It is speculated that $235^{+}$and $217^{+}$are adduct ions that form as a result of reactions occurring between TBP and some contaminant on the surface of the sample. 
Table 5. Assignment of cations observed in the SIM spectrum of TBP on basalt.

\begin{tabular}{lll}
\hline $\mathrm{m} / \mathrm{z}$ & \multicolumn{1}{c}{ Assignment } \\
\hline $267^{+}$ & {$[\mathrm{M}+\mathrm{H}]^{+}$, barely $>$background } \\
$249^{+}$ & $267^{+}-\mathrm{H}_{2} \mathrm{O}$ \\
$235^{+}$ & unknown, $267^{+}-\mathrm{CH}_{3} \mathrm{OH} ?$ \\
$217^{+}$ & unknown, 249+ $-\mathrm{CH}_{3} \mathrm{OH} ?$ \\
$193^{+}$ & $267^{+}-\mathrm{C}_{4} \mathrm{H}_{9} \mathrm{OH}$, or $249^{+}-\mathrm{C}_{4} \mathrm{H}_{8}$ \\
$175^{+}$ & $193^{+}-\mathrm{H}_{2} \mathrm{O}$, low abundance \\
$155^{+}$ & $267^{+}-2\left(\mathrm{C}_{4} \mathrm{H}_{8}\right)$ \\
$137^{+}$ & $193^{+}-\mathrm{C}_{4} \mathrm{H}_{8}$, or $155^{+}-\mathrm{H}_{2} \mathrm{O}$ \\
$119^{+}$ & $193^{+}-\mathrm{C}_{4} \mathrm{H}_{9} \mathrm{OH}$, or $137^{+}-\mathrm{H}_{2} \mathrm{O}$ \\
$99^{+}$ & $\mathrm{H}_{4} \mathrm{PO}_{4}^{+}$ \\
$81^{+}$ & $\mathrm{H}_{2} \mathrm{PO}_{3}^{+}$ \\
\hline
\end{tabular}

Table 6. Assignment of cations observed in the SIM spectrum of $250 \mathrm{ng}$ TBP on sandstone.

\begin{tabular}{ll}
$\mathrm{m} / \mathrm{z}$ & \multicolumn{1}{c}{ Assignment } \\
\hline $267^{+}$ & {$[\mathrm{M}+\mathrm{H}]^{+}$} \\
$249^{+}$ & $267^{+}-\mathrm{H}_{2} \mathrm{O}$ \\
$211^{+}$ & $267^{+}-\mathrm{C}_{4} \mathrm{H}_{8}$ \\
$155^{+}$ & $211^{+}-\mathrm{C}_{4} \mathrm{H}_{8}$ \\
$153^{+}$ & unknown \\
$137^{+}$ & $211^{+}-\mathrm{C}_{4} \mathrm{H}_{9} \mathrm{OH}$, or $155^{+}-\mathrm{H}_{2} \mathrm{O}$ \\
$125^{+}$ & $\mathrm{C}_{2} \mathrm{H}_{6} \mathrm{PO}_{4}^{+}$isomer \\
$119^{+}$ & $137^{+}-\mathrm{H}_{2} \mathrm{O}$ \\
$99^{+}$ & $\mathrm{H}_{4} \mathrm{PO}_{4}^{+}$ \\
$81^{+}$ & $\mathrm{H}_{2} \mathrm{PO}_{3}^{+}$ \\
\hline
\end{tabular}

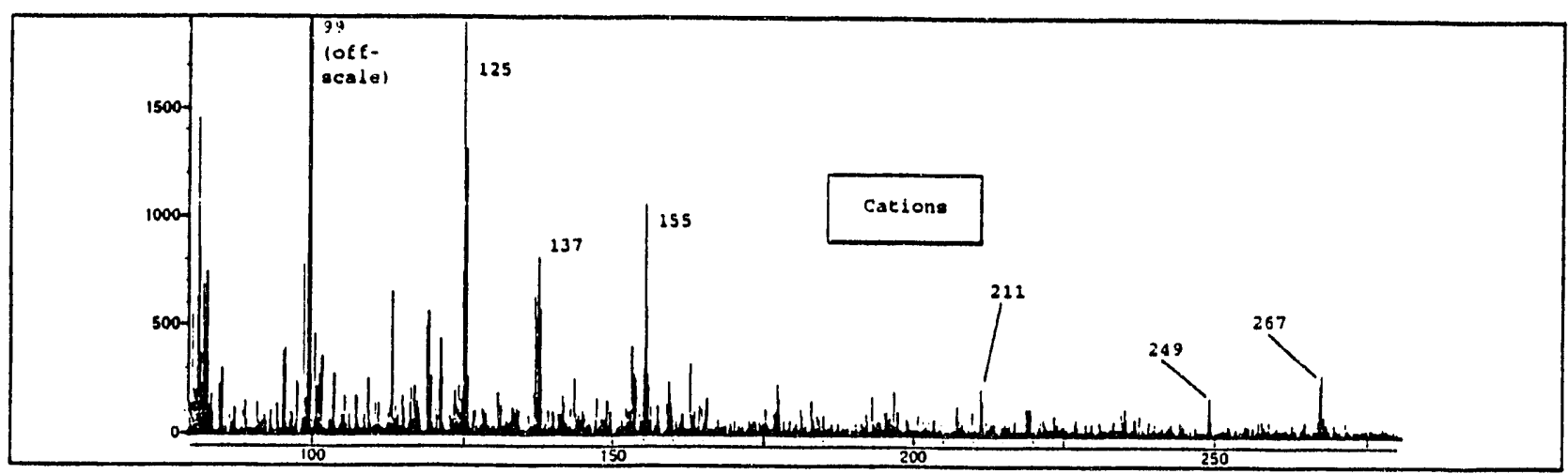

Figure 21. Cation SIM spectrum of $250 \mathrm{ng}$ TBP on sandstone. 


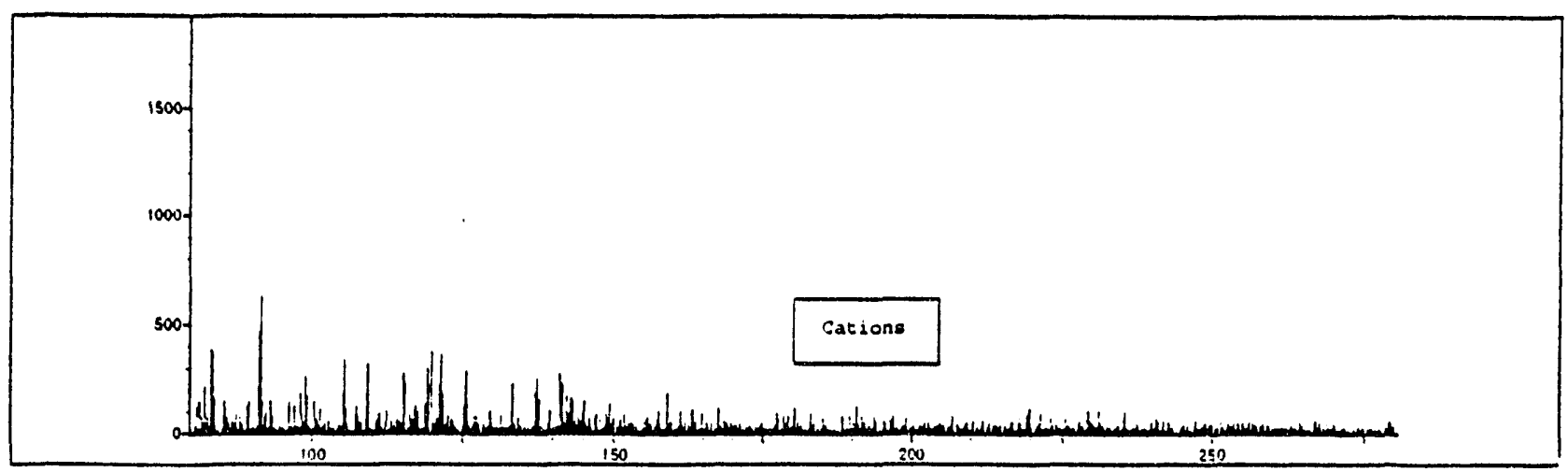

Figure 22. Cation SIM spectrum of benchmark (unspiked) sandstone.

\subsection{TBP on Soil}

Samples were collected from fill dirt obtained locally (i.e., Dr. Ingram's garden) and attached to target planchettes for MBSA analysis. Soil was analyzed unspiked and spiked with TBP. Attachment of the soil sample to the planchette was performed in several ways: the soil was pressed into a pellet and stuck onto the planchette using rubber cement; the soil was pressed into indium foil, and the foil was glued onto the planchette; and the soil stuck to the planchette using double-sided tape. Care was necessary in this process to avoid dropping dirt into the turbo pump. The SIM spectra that were obtained were similar irrespective of the attachment method used.

When the unspiked soil samples were admitted to the MBSA instrument and analyzed, many cations were observed in the SIM spectrum that were identical to the ions attributed to TBP in the rock and steel experiments mentioned above (see Figure 23). Further, it was noted that the SIM spectra of the TBP-spiked soil samples were identical to the spectra of the unspiked samples. There are two possible explanations for these observations; (1) the soil sample contains alkyl phosphates (perhaps even TBP) that give nearly an identical set of secondary ions; (2) the soil contains other chemicals that give a set of ions consistent with TBP. The former explanation is the most plausible. 


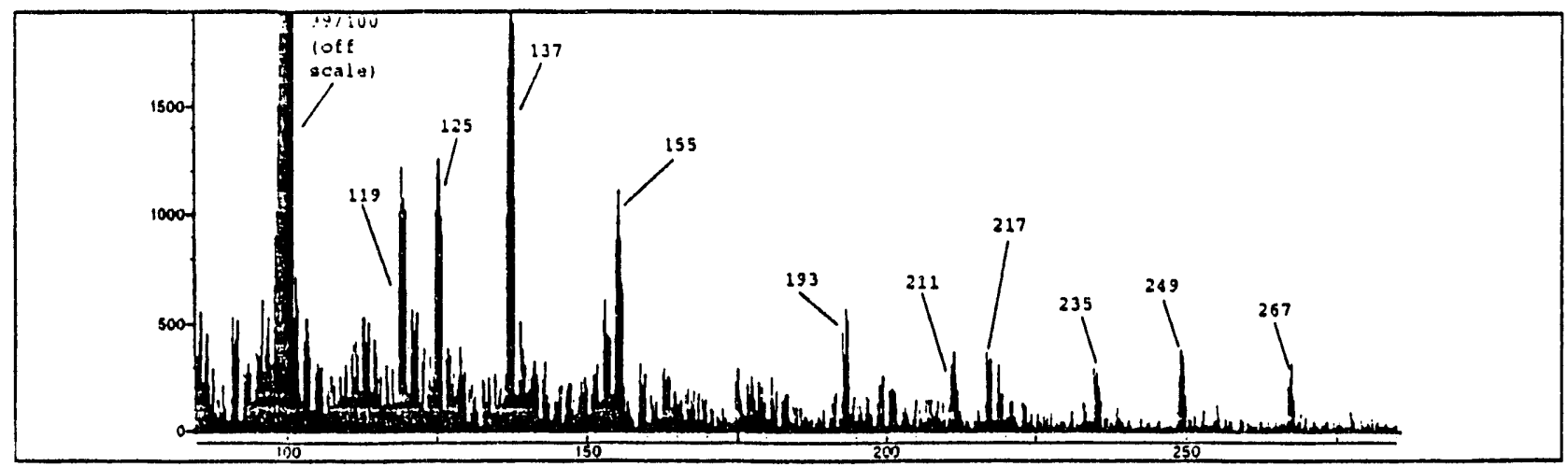

Figure 23. Cation SIM spectrum of unspiked soil. 


\section{CARBOXYLIC ACID STUDIES}

A variety of carboxylic acids were studied to understand their fragmentation chemistry during MBSA analysis and to identify ions for use in detection on environmental samples. During 1992, benchmark spectra of the carboxylic acids were obtained, but evaluation of their detection on environmental surfaces was just barely initiated, and at this time, a limited amount of data exists for the carboxylic acids on environmental surfaces.

\subsection{Carboxylic Acid Powders}

The carboxylic acids that were studied are those that have had utility at DOE facilities, and their structures are presented in Figure 24. Carboxylic acid powders were attached to target planchettes using double-sided tape and admitted to the MBSA instrument for analysis. The spectra that were obtained for these acids had features that were similar, and these features are summarized in Tables 7 (cations) and 8 (anions).

Similar cation spectra were obtained for all the carboxylic acids with the exception of citric acid, which displayed no ions above background. $(\mathrm{M}+\mathrm{H})^{+}$ions were observed in all spectra (except for citric), and $(\mathrm{M}+\mathrm{Na})^{+}$was observed when sodium was present. A typical spectrum is shown in Figure 25 (for ascorbic acid). A proton-bound dimer ion $(2 \mathrm{M}+\mathrm{H})^{+}$was observed in the oxalic acid spectrum; it is believed that this ion may be observable for the other acids, but the instrument was not scanned to a high enough $\mathrm{m} / \mathrm{z}$ value to verify this. Fragment ions generally corresponded to the loss(es) of $\mathrm{H}_{2} \mathrm{O}, \mathrm{CO}$ and/or combinations thereof (see Table 7). In addition to the ions described above, the spectrum of ascorbic acid contained abundant ions at $\mathrm{m} / \mathrm{z} 92^{+}$and $146^{+}$, and to date, these ions have not been identified. Similarly, ions at $\mathrm{m} / \mathrm{z} 129^{+}, 116^{+}$, and $113^{+}$have not been identified in the spectrum obtained from ascorbic acid.

A notable feature in many of the cation SIM spectra is the presence of an abundant $\mathrm{m} / \mathrm{z} 100^{+}$ ion (see Figure 25). This ion is occasionally observed in the spectra of acidic materials, whether they are capable of forming $\mathrm{m} / \mathrm{z} 100^{+}$or not. Accordingly, it is thought that this ion is an artifact of the surface of the material being analyzed (e.g., stainless steel, double-sided tape) and may not be ascribable to the analyte.

In the anion spectra, (M-H) ions were always observed, and if sodium was present, then $(\mathrm{M}-2 \mathrm{H}+\mathrm{Na})^{-}$ions were also observed. An abundant ion corresponding to $(2 \mathrm{M}-\mathrm{H})^{-}$was observed in the anion spectrum of oxalic acid; it is believed that this ion may be observable for the other acids, but the instrument was not scanned to a high enough $\mathrm{m} / \mathrm{z}$ value to verify this. The fragment ions observed in the anion spectra of the acids generally correspond to the losses of $\mathrm{H}_{2} \mathrm{O}, \mathrm{CO}, \mathrm{CO}_{2}$, and/or combinations of these molecules (see Table 8). The anion spectrum of ascorbic acid is an exception to this behavior. In this case, the base peak is observed at $\mathrm{m} / \mathrm{z} 115^{\circ}$ (see Figure 25 ), and it is hypothesized that it can be accounted for by the elimination of $\mathrm{HOCH}_{2} \mathrm{CHO}$ from the (M-H) ion to form a stable ion having a hydroxylated furan structure (see Figure 26). 


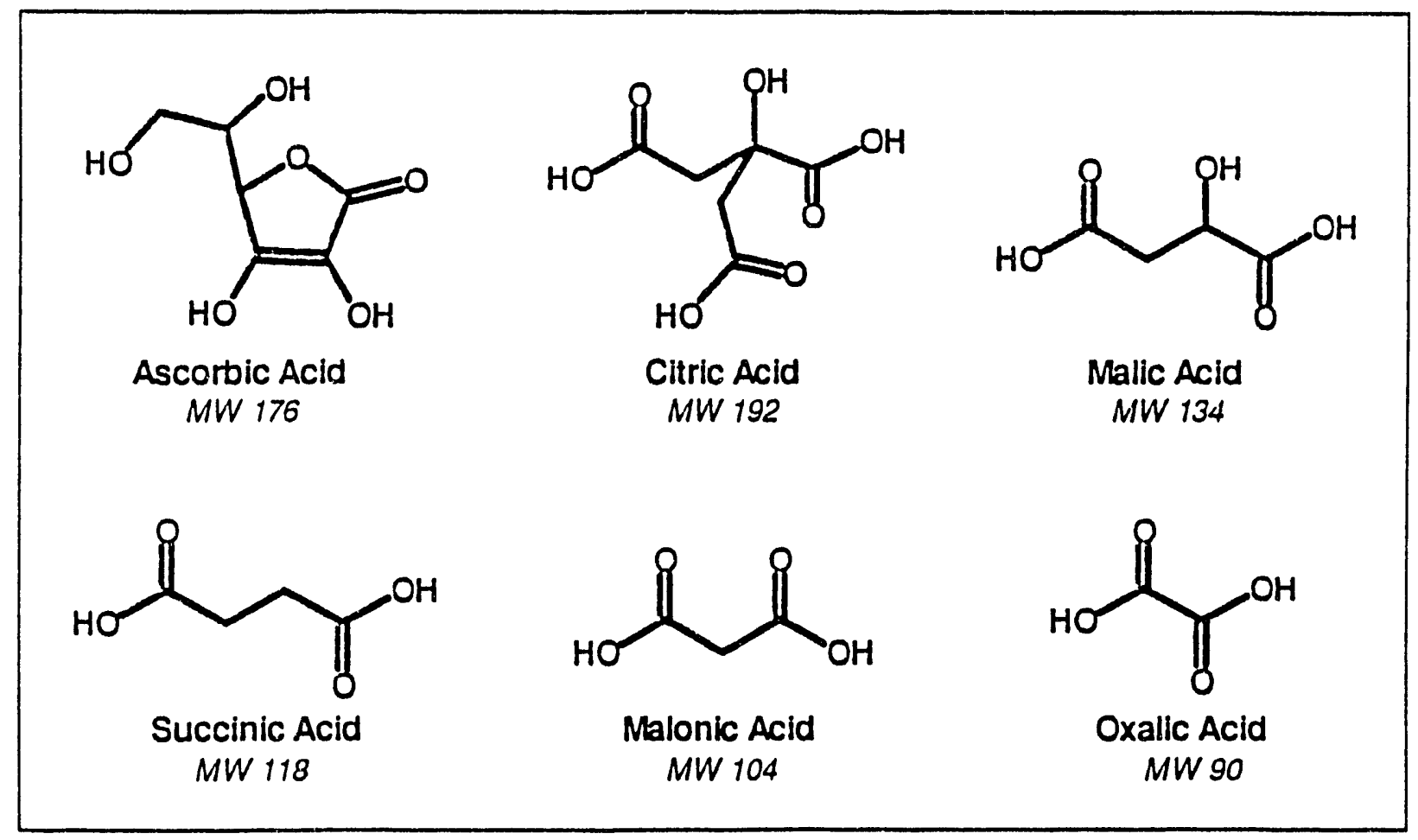

Figure 24. Structures of carboxylic acids.

Table 7. Summary of salient cations observed in the SIM spectra of carboxylic acid powders.

\begin{tabular}{|c|c|c|c|c|c|c|}
\hline Ion identity & $\begin{array}{l}\text { Oxalic acid } \\
\mathrm{m} / \mathrm{z}\end{array}$ & $\begin{array}{l}\text { Malonic acid } \\
\mathrm{m} / \mathrm{z}\end{array}$ & $\begin{array}{l}\text { Succinic acid } \\
\mathrm{m} / \mathrm{z}\end{array}$ & $\begin{array}{l}\text { Malic acid } \\
\mathrm{m} / \mathrm{z}\end{array}$ & $\begin{array}{c}\text { Ascorbic acid } \\
\mathrm{m} / \mathrm{z}\end{array}$ & $\begin{array}{c}\text { Citric acid } \\
\mathrm{m} / \mathbf{z}\end{array}$ \\
\hline$(2 \mathrm{M}+\mathrm{H})^{+}$ & $181^{+}$ & $\mathrm{no}^{\mathrm{a}}$ & $\mathrm{no}^{\mathrm{a}}$ & $\mathrm{no}^{\mathrm{a}}$ & $\mathrm{no}^{\mathrm{a}}$ & no $^{c}$ \\
\hline $\begin{array}{l}(\mathrm{M}- \\
\mathrm{H}+2 \mathrm{Na})^{+}\end{array}$ & no ${ }^{b}$ & no ${ }^{b}$ & $n o^{b}$ & $179^{+}$ & $221^{+}$ & no ${ }^{c}$ \\
\hline$(\mathrm{M}+\mathrm{Na})^{+}$ & no ${ }^{b}$ & $127^{+}$ & $n o^{b}$ & $157^{+}$ & $199^{+}$ & no ${ }^{c}$ \\
\hline$(\mathrm{M}+\mathrm{H})^{+}$ & $91^{+}$ & $105^{+}$ & $119^{+}$ & $135^{+}$ & $177^{+}$ & $n^{c}$ \\
\hline $\begin{array}{l}(\mathrm{M}+\mathrm{H})^{+}- \\
\mathrm{H}_{2} \mathrm{O}\end{array}$ & $-d$ & $87^{+}$ & $101^{+}$ & $117^{+}$ & no ${ }^{b}$ & no ${ }^{c}$ \\
\hline $\begin{array}{l}(\mathrm{M}+\mathrm{H})^{+} \\
\mathrm{H}_{2} \mathrm{O}-\mathrm{CO}\end{array}$ & $-d$ & $-^{d}$ & $-^{d}$ & $89^{+}$ & no ${ }^{b}$ & no ${ }^{c}$ \\
\hline $\begin{array}{l}(\mathrm{M}+\mathrm{H})^{+} \\
2 \mathrm{H}_{2} \mathrm{O}\end{array}$ & $-^{d}$ & $-^{d}$ & $-{ }^{d}$ & $99^{+}$ & $141^{+}$ & no ${ }^{c}$ \\
\hline \multicolumn{7}{|c|}{$\begin{array}{l}\text { a. Not observed in the cation SIM spectrum because instrument not scanned to }(2 \mathrm{M}-\mathrm{H})^{\circ} \text {. } \\
\text { b. Not observed in the cation SIM spectrum. }\end{array}$} \\
\hline \multicolumn{7}{|c|}{$\begin{array}{l}\text { c. No ions observed above background in the cation SIM spectrum of citric acid. } \\
\text { d. Ions observed corresponding to these losses, but could not be unequivocally ascribed to analyte } \\
\text { because of isobaric background ions. }\end{array}$} \\
\hline
\end{tabular}


Table 8. Summary of salient anions observed in the SIM spectra of carboxylic acid powders.

\begin{tabular}{|c|c|c|c|c|c|c|}
\hline Ion identity & $\begin{array}{l}\text { Oxalic acid } \\
\qquad \mathrm{m} / \mathrm{z}\end{array}$ & $\begin{array}{l}\text { Malonic acid } \\
\mathrm{m} / \mathrm{z}\end{array}$ & $\begin{array}{l}\text { Succinic acid } \\
\mathrm{m} / \mathrm{z}\end{array}$ & $\begin{array}{l}\text { Malic acid } \\
\mathrm{m} / \mathrm{z}\end{array}$ & $\begin{array}{c}\text { Ascorbic acid } \\
\mathrm{m} / \mathrm{z}\end{array}$ & $\begin{array}{c}\text { Citric acid } \\
\mathrm{m} / \mathrm{z}\end{array}$ \\
\hline$(2 \mathrm{M}-\mathrm{H})^{\circ}$ & $179^{\circ}$ & $n o^{b}$ & $n o^{b}$ & $n o^{b}$ & $n o^{b}$ & no ${ }^{b}$ \\
\hline$(\mathrm{M}-2 \mathrm{H}+\mathrm{Na})^{-}$ & no ${ }^{a}$ & $125^{\circ}$ & no ${ }^{a}$ & $155^{\circ}$ & $197^{\circ}$ & $\mathrm{no}^{\mathrm{a}}$ \\
\hline$(\mathrm{M}-\mathrm{H})^{\cdot}$ & $89^{\circ}$ & $103^{\circ}$ & $117^{\circ}$ & $133^{\circ}$ & $175^{\circ}$ & $191^{\circ}$ \\
\hline$(\mathrm{M}-\mathrm{H})^{-}-\mathrm{H}_{2} \mathrm{O}$ & $\mathrm{no}^{\mathrm{a}}$ & $85^{\circ}$ & $99^{-}$ & $115^{\circ}$ & no ${ }^{a}$ & $173^{-}$ \\
\hline$(\mathrm{M}-\mathrm{H})^{-}-\mathrm{CO}$ & $61^{\circ}$ & $75^{\circ}$ & no $^{\mathrm{a}}$ & no ${ }^{a}$ & no ${ }^{a}$ & $n^{a}$ \\
\hline $\begin{array}{l}(\mathrm{M}-\mathrm{H})^{-} \\
2 \mathrm{H}_{2} \mathrm{O}\end{array}$ & $\mathrm{no}^{\mathrm{a}}$ & no $^{\mathrm{a}}$ & no ${ }^{a}$ & no ${ }^{a}$ & no ${ }^{a}$ & $155^{\circ}$ \\
\hline$(\mathrm{M}-\mathrm{H})^{\cdot}-\mathrm{CO}_{2}$ & $45^{\circ}$ & $59^{-}$ & $73^{\circ}$ & $89^{\circ}$ & $\mathrm{no}^{\mathrm{a}}$ & $n o^{a}$ \\
\hline $\begin{array}{l}(\mathrm{M}-\mathrm{H})^{-}- \\
\mathrm{HOCH}_{2} \mathrm{CHO}\end{array}$ & $\mathrm{no}^{\mathrm{a}}$ & $\mathrm{no}^{\mathrm{a}}$ & $\mathrm{no}^{\mathrm{a}}$ & $\mathrm{no}^{\mathrm{a}}$ & $115^{\circ}$ & $\mathrm{no}^{\mathrm{a}}$ \\
\hline $\begin{array}{l}(\mathrm{M}-\mathrm{H})^{-}-\mathrm{CO}_{2} \\
-\mathrm{H}_{2} \mathrm{O}\end{array}$ & $\mathrm{no}^{\mathrm{a}}$ & no ${ }^{a}$ & $55^{\circ}$ & $71^{\circ}$ & $113^{\circ}$ & $129^{\circ}$ \\
\hline $\begin{array}{l}(\mathrm{M}-\mathrm{H})^{-} \cdot \mathrm{CO}_{2} \\
-2 \mathrm{H}_{2} \mathrm{O}\end{array}$ & $\mathrm{no}^{\mathrm{a}}$ & no ${ }^{a}$ & $\mathrm{no}^{\mathrm{a}}$ & $\mathrm{no}^{\mathrm{a}}$ & $\mathrm{no}^{\mathrm{a}}$ & $111^{-}$ \\
\hline
\end{tabular}

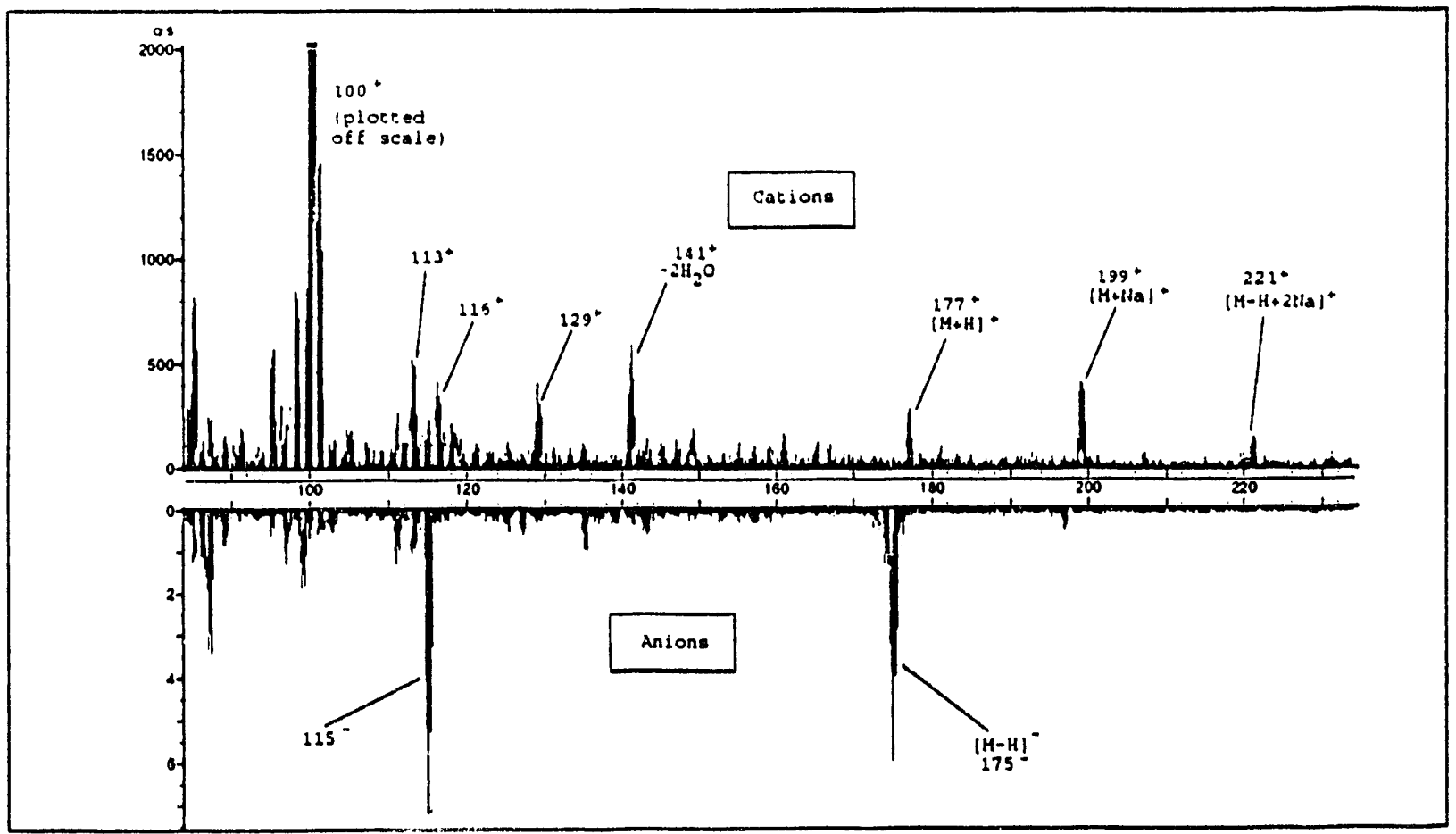

Figure 25. Partial cation (top) and anion (bottom) SIM spectra of ascorbic acid powder, which was adhered to the planchette with double-sided tape. 


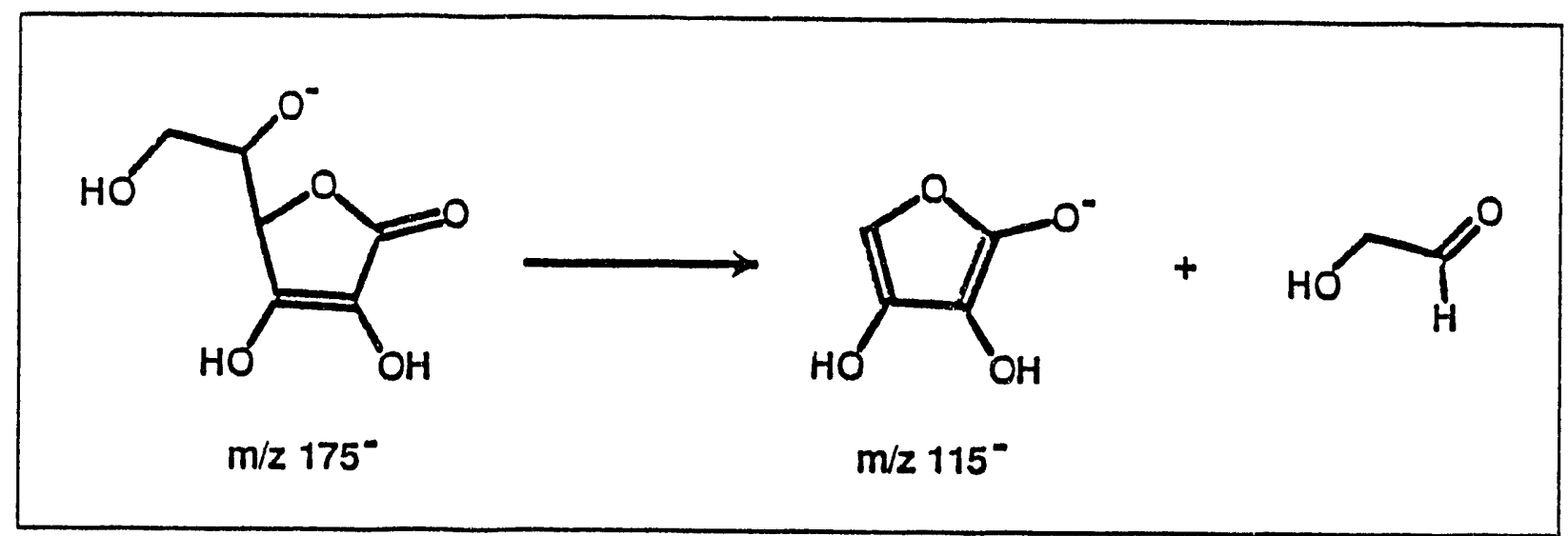

Figure 26. Scheme proposed for the formation of $\underline{\mathrm{m} / \mathrm{z}} 115^{\circ}$ (base peak) in the anion SIM spectrum of ascorbic acid.

\subsection{Carboxylic Acids on Environmental Surfaces}

These studies have just begun, and little data have been collected as of September 1992. Microgram quantities of oxalic acid have been analyzed on stainless steel. No cations were detected above the background, but the anions identified in Table 8 were clearly above the background (see Figure 27). This result is significant because analytes that are detectable on stainless steel can usually be detected on rocks. 


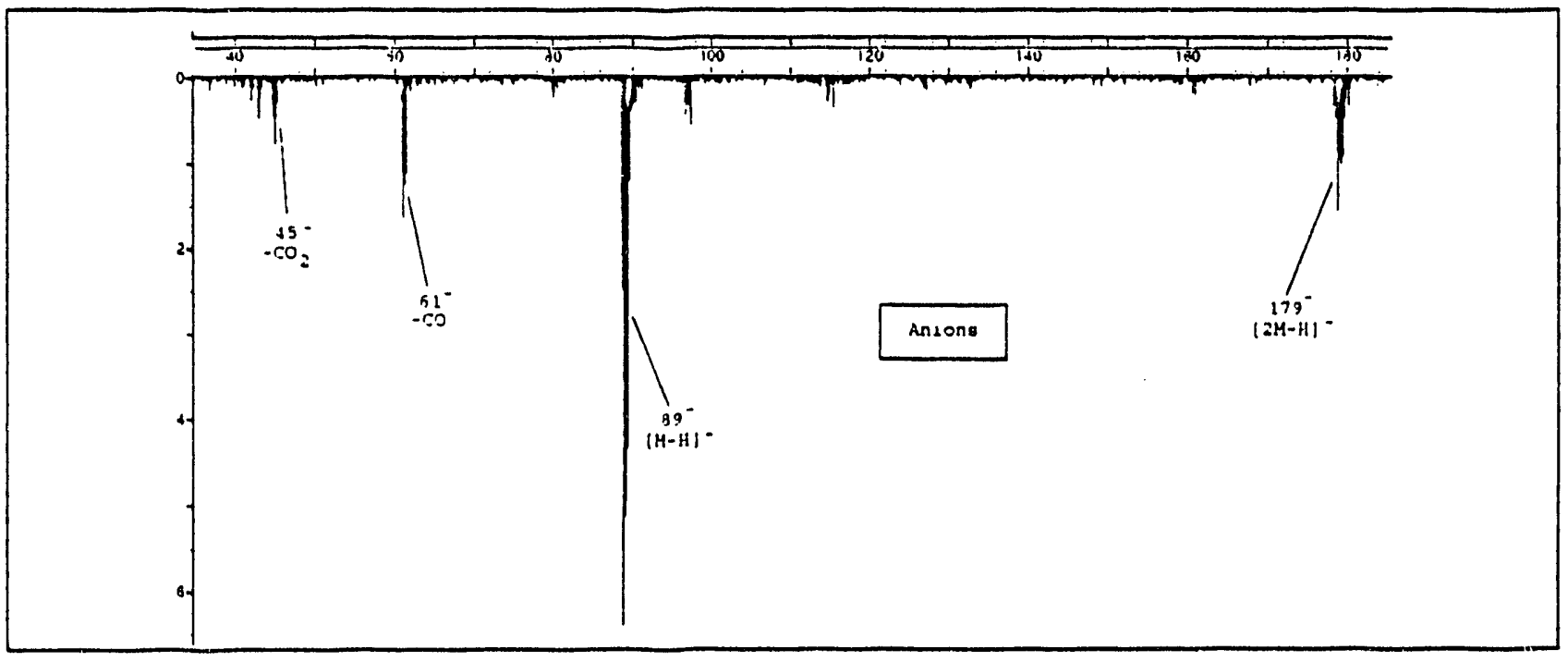

Figure 27. Anion SIM spectrum of oxalic acid on stainless steel. 


\section{CONCLUSIONS AND RECOMMENDATIONS}

MBSA or in situ SIMS is capable of directly detecting TBP on rocks and other surfaces with little or no sample preparation. EDTA (and probably other chelating agents) are more difficult to detect, because they are very reactive with surfaces of interest. Nevertheless, it appears that it is possible to detect EDTA if the acidity of the surface is controlled. The ability to detect EDTA-metal complexes is currently an open question. Other carboxylic acids give characteristic SIM spectra, but their detection on sample surfaces awaits evaluation.

\subsection{EDTA and Transition Metals}

EDTA is a challenging analytical target, because it binds strongly to sample surfaces, and is easily fragmented when subjected to primary ion bombardment. These characteristics are manifested in a wide variety of chemistry, and as a result, there is a great potential for generating information on metals in the environment at DOE sites.

EDTA can be observed on stainless steel and rocks when it is deposited at lower pH values. At this time, the observation of EDTA deposited on surfaces from higher $\mathrm{pH}$ solutions remains problematic. The presence of metals or anions on the sample surface has a dramatic effect on the SIM spectra of EDTA. The fregmentation chemistry of EDTA is altered by the presence of alkali metal cations $\left(\mathrm{Na}^{+}\right)$and also by transition metal dications $\left(\mathrm{Co}^{+2}, \mathrm{~Pb}^{+2}\right)$. Both transition metals studied ( +2 oxidation state) produced abundant ions corresponding to $\mathrm{M}\left(\mathrm{X}_{3}\right)^{-}$, where $\mathrm{X}$ is the monovalent counter anion $\left(\mathrm{Cl}^{-}\right.$or $\left.\mathrm{NO}_{3}{ }^{\circ}\right)$. However, it has been difficult to observe ions corresponding to metal-EDTA complexes. The presence of Group VII halides, salts, or polymers tends to suppress the formation (or observation) of ions from EDTA.

Several needs exist to develop an understanding sufficient to utilize MBSA for the detection of EDTA in the environment. These include

- Expanding the EDTA-lead research, using different counter ions, to confirm the presence of lead EDTA ions

- Understanding the effect of different counter anions (i.e., halides, nitrate, carbonate) on the SIM spectra of EDTA

- Understanding the effect of different alkali cations on the SIM spectra of EDTA

- Fxpanding the research to include additional metals (specifically mercury, strontium, and cesium) (see Figure 4)

- Expanding the research to include a broader variety of rocks, concrete, and asphalt (see Figure 4)

- Exploration of new techniques for the analysis of soil for EDTA 
- Examination of other transition metal species (e.g., oxides) on surfaces, both with and without EDTA

- Evaluation of the related compounds DTPA and NTA.

\subsection{TBP}

TBP can be readily detected on basalt and sandstone to levels of $250 \mathrm{ng}$, with no optimization of the analysis. A cation spectrum is observed that is consistent with the structure of the compound. The cation spectrum is affected by the presence of sodium, and this observation indicates that it may be possible to observe other TBP-metal complexes. Significant anions are also detected, and these are not as affected by the presence of sodium, but their abundance is lower than that of the cations. The attempts to detect TBP in soil have not been successful to date, and this may be due to the absorptive nature of the soil or the presence of related compounds that produce SIM spectra similar to TBP.

MBSA technology could be employed for TBP detection on basalt or sandstone with detection limits to $250 \mathrm{ng}$. An enhanced understanding of the chemistry would broaden the applicability of the technique and aid in elucidating the surface chemistry of TBP. Toward these ends, the following needs are outstanding:

- Optimization and determination of detection limits for TBP on different types of rocks

- Analysis of TBP in the presence of metals other than sodium: cobalt, strontium, cesium, lead, and mercury

- Understanding of the origins of ions observed in the spectra of soil.

\subsection{Carboxylic Acids}

MBSA analysis of carboxylic acids results in SIM spectra that are characteristic of these compounds. Ions observed in these analyses certainly have analytical utility for detection, but this utility has not yet been demonstrated. Several needs exist to pursue this application:

- Carboxylic acids need to be analyzed on a variety of surfaces

- Influence of metals other than sodium needs to be assessed

- Detection limits and potential interferences need to be evaluaied. 


\section{REFERENCES}

1. J. E. Delmore and A. D. Appelhans, Biological Mass Spectrometry, 20, 1991. pp. 237-246.

2. R. G. Riley and J. M. Zachara, Nature of Chemical Contaminants on DOE Lands and Identification of Representative Contaminant Mixtures for Basic Subsurface Science Research, Draft, Pacific Northwest Laboratory, Richland, WA, 99352, June 1991.

3. A. J. Francis, "Low-Level Radioactive Wastes in Subsurface Soils," Soil Reclamation Processes, Marcel Dekker, Inc., New York, NY, 1985, pp. 279-331.

4. T. F. Rees and J. M. Cleveland, "Characterization of Plutonium in Waters at Maxey Flats, Kentucky, and Near the Idaho Chemical Processing Plant, Idaho," Environmental Migration of Long-Lived Radionuclides, Proceedings of a Symposium Knoxville, July 27-31, 1981, International Atomic Energy Agency, Vienna, 1982.

5. L. J. Kirby, A. P. Toste, and C. L. Wilkerson, "Chemical Species of Migrating Radionuclides at a Shallow Land Low-Level Radioactive Waste Burial Site," Environmental Migration of Long-Lived Radionuclides, Proceedings of a Symposium Knoxville, July 27-31, 1981, International Atomic Energy Agency, Vienna, 1982.

6. J. L. Means, D. A. Crerar, and J. O. Duguid, "Migration of Radioactive Wastes: Radionuclide Mobilization by Complexing Agents," Science, 200, 1978, pp. 1477-1481.

7. Basic Research Needs for Management and Disposal of DOE Wastes, U.S. Department of Energy Office of Energy Research, Washington, D.C., 20585, April 1991.

8. Underground Storage Tank Waste Characterization Needs Assessment Workshop, U.S. Department of Energy, WHC-EP-0514, June 1992.

9. S. L. Lopez, Scoping Investigation Sampling and Analysis Plan Field Sampling Plan for Pad A of the Radioactive Waste Management Complex at the Idaho National Engineering Laboratory, EG\&G Idaho, Inc., EGG-WM-9626, Revision 0, July 1991.

10. J. M. Beller and R. A. Bessent, Test Reactor Area Warm Waste Pond at the Idaho National Engineering Laboratory Sediment Treatability Study Phase I Report, EG\&G Idaho, Inc., EGG-WM-10000, Revision 0, November 1991. 
$\nabla$
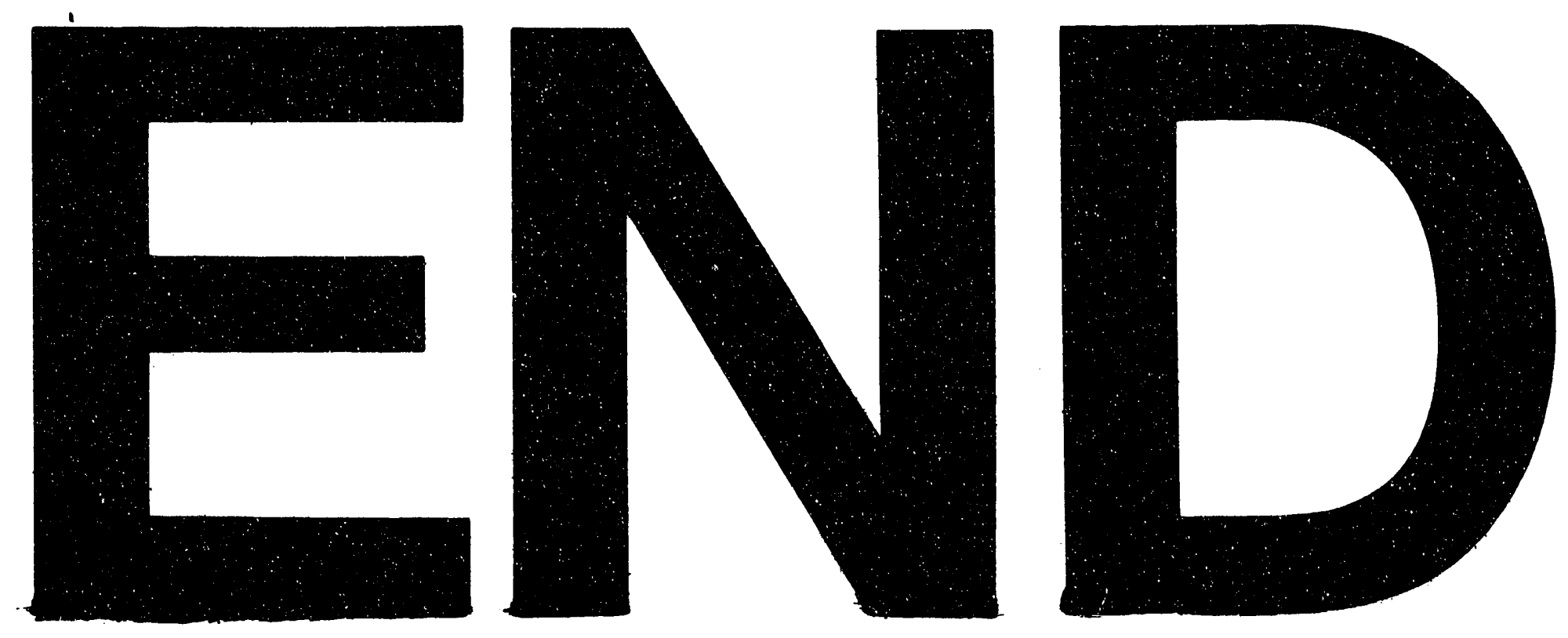

줄

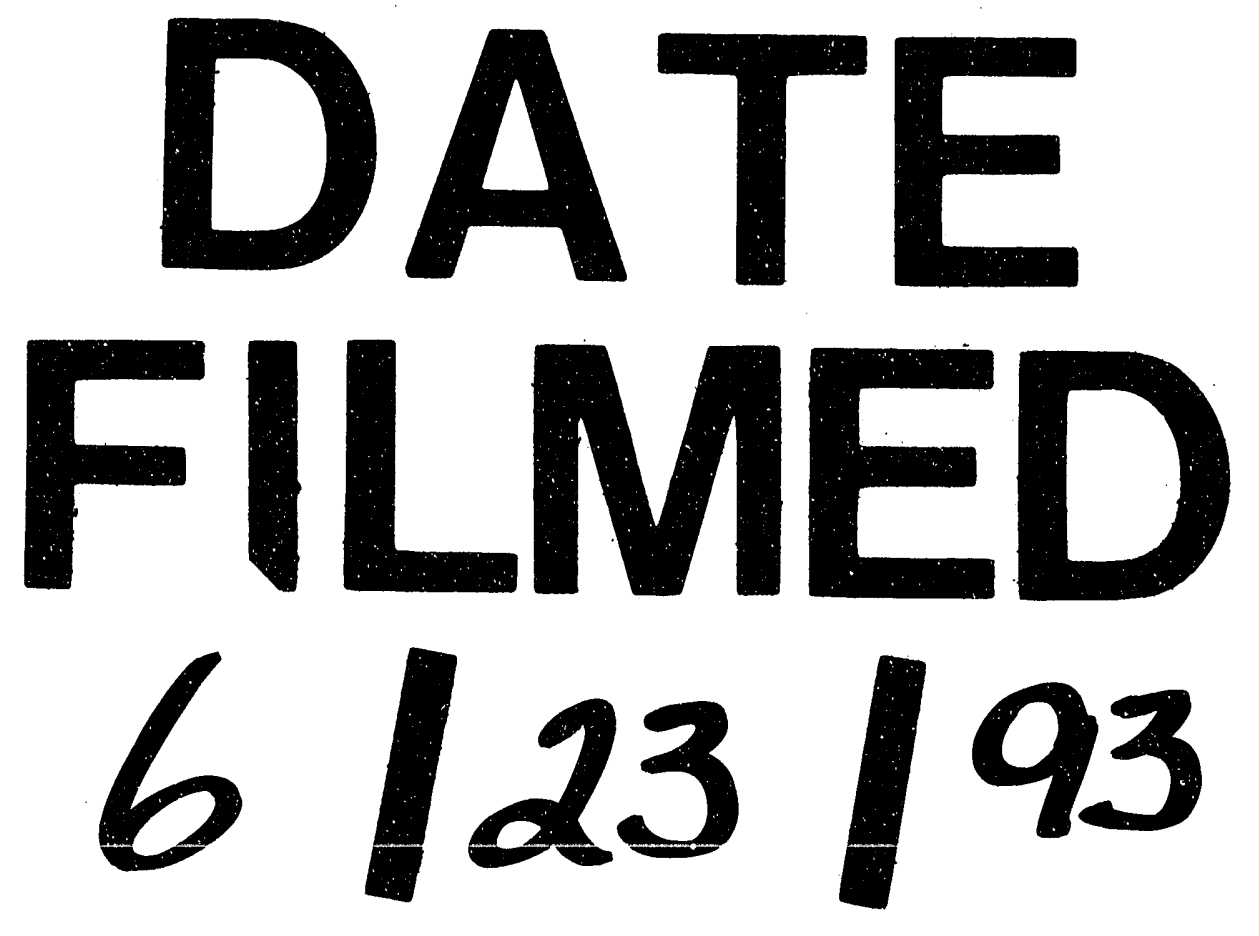


